\title{
TEMPERAMENT AND SYMPTOM PATHWAYS TO THE DEVELOPMENT OF ADOLESCENT DEPRESSION
}

\author{
by \\ LUCIANO DOLCINI-CATANIA
}

\begin{abstract}
A THESIS
Presented to the Department of Psychology and the Robert D. Clark Honors College

in partial fulfillment of the requirements for the degree of

Bachelor of Science
\end{abstract}

December 2015 


\section{An Abstract of the Thesis of}

Luciano Dolcini-Catania for the degree of Bachelor of Science in the Department of Psychology to be taken December 2015

Title: Temperament and Symptom Pathways to the Development of Adolescent Depression

Approved:

Dr. Nicholas B. Allen

This study examined the influence of internalizing and externalizing symptoms during early adolescence on the subsequent development of depressive disorder. The role that temperament plays in predisposing individuals to these particular pathways was also examined. Logistical regression analyses revealed that internalizing symptoms and social-externalizing problems were significant risk pathways to the development of depression. Moreover, mediation analyses revealed that high negative emotionality, high affiliation, low effortful control and low surgency were significant vulnerability factors for the internalizing symptom pathway, whereas low effortful control was the only significant mediational predictor for the social-externalizing problem pathway. As such, high levels of effortful control acted as a protective factor for the development of depression across both symptom pathways, suggesting that is may be an important target for prevention strategies. 


\section{Acknowledgements}

I would like to thank Dr. Nicholas Allen, Dr. Michelle Byrne, Dr. Barbara Mossberg, Dr. Peggy Dolcini, Dr. Joseph Catania, Ang, Alison, Eva, Miriam Rigby and Miriam Jordan for all of the help and support over the past year. I am extraordinarily grateful to have worked directly with Nick in a one-on-one setting throughout the entire thesis process. Nick gave exemplary feedback during each stage of research and writing, and his mentorship and wisdom extended beyond an academic setting. I appreciate Nick's approachable and relatable demeanor, and that he has turned me on to some killer bands. This is a privilege few undergraduates experience and I couldn't be more thankful. Michelle provided invaluable insight into the structure and analysis of my thesis, and ensured that I had the raw materials needed at each stage of the process. Dr. B is a true inspiration, and her support, energy, and mentorship over the past year have fundamentally altered my worldview. Dr. B is a catalyst to genius and selfdiscovery and provides an archetype for teachers everywhere. Her presence is a true blessing. My family and friends provided the emotional scaffolding that supported me through the ebb and flow of the past year. Miriam Jordan, you rock! Thank you for helping out behind the scenes; not only in respect to my own thesis, but for the hundreds of students you help each year. Lastly, thank you Miriam Rigby and all of the other librarians who played a role in my research along the way. 


\section{Table of Contents}

List of Tables viii

Introduction 1

Study Overview 1

Adolescent Depression 2

The Etiology of Mental Health Disorders During Adolescence: Internalizing, Externalizing, and Temperamental $\quad 4$

Internalizing symptoms and disorders. $\quad 4$

Externalizing symptoms and disorders: Comorbidity with internalizing symptoms and disorders. $\quad 5$

Internalizing and externalizing pathways to Major Depressive Disorder $\quad 7$

Temperament as a Risk Factor For Internalizing and Externalizing Symptoms

Temperament and Interpersonal Problems $\quad 11$

Conceptualization of Temperament in Adolescence 12

$\begin{array}{ll}\text { Summary of Current Literature Review } & 13\end{array}$

$\begin{array}{ll}\text { Hypotheses } & 14\end{array}$

$\begin{array}{ll}\text { Methods } & 16\end{array}$

Design 16

$\begin{array}{ll}\text { Participants } & 16\end{array}$

$\begin{array}{ll}\text { Results } & 22\end{array}$

Data Screening and Missing Data $\quad 22$

$\begin{array}{ll}\text { Descriptive Statistics } & 22\end{array}$

Inter-correlations and Data Reduction 23

Between Group Differences $\quad 27$

Prediction of Onset of Major Depressive Disorder 30

Mediational Analyses 33

Discussion $\quad 41$

Overview of Results $\quad 41$

Symptom Pathways and Major Depressive Disorder 42

Temperament, Symptom Pathways, and Major Depressive Disorder 43

Theoretical Implications $\quad 45$

Additional Limitations and Strengths $\quad 48$ 
Future Research and Interventions

Conclusion

52

Bibliography 


\section{List of Accompanying Materials}

1. Early Adolescent Temperament Questionnaire - Revised

2. Center for Epidemiological Studies Depression Scale

3. Beck Anxiety Inventory

4. Child Behavior Check List, Parent Version 


\section{List of Figures}

Figure 1 - Temperamental Pathway Toward Major Depressive Disorder

Figure 2 - Hypothesized Specific Pathways Toward MDD (Red arrows represent the hypothesized the externalizing pathway. Purple arrows represent the hypothesized internalizing pathway)

Figure 3 - Flow Chart of Data Collection by Wave

Figure 4 - Mediation among negative emotionality (NEM), internalizing symptoms (INT), and Major Depressive Disorder (MDD)

Figure 5 - Mediation among surgency (SUR), internalizing symptoms (INT), and Major Depressive Disorder (MDD)

Figure 6 - Mediation among affiliativeness (AF), internalizing symptoms (INT), and Major Depressive Disorder (MDD)

Figure 7 - Mediation among effortful control (EC), internalizing symptoms (INT), and Major Depressive Disorder (MDD)

Figure 8 - Mediation among effortful control (EC), social problems (SOC), and Major Depressive Disorder (MDD)

Figure 9 - Established Specific Pathways Towards MDD (Red arrows represent the social-externalizing pathway. Purple arrows represent the internalizing pathway) 


\section{List of Tables}

Table 1 - Temperamental Dimensions and Related Concepts 9

Table 2 - Descriptive Statistics Symptom Questionnaires T1 23

Table 3 - Descriptive Statistics Temperament T1 23

Table 6 - Rotated Component Matrix ${ }^{\mathrm{a}} \quad 27$

Table 9 - Temperamental Differences Between Individuals With and Without MDD 30

Table 10 - Temperamental Differences Between Sexes 30

Table 11 - Summary of a Series of Logistic Regression Analyses (controlling for sex), with Internalizing Symptoms and Respective Externalizing Symptoms at T1 Predicting Diagnosis of Major Depressive Disorder

Table 12 - Summary of Logistic Regression Moderation Analysis for Internalizing Symptoms and Temperament at T1

Table 13 - Summary of Logistic Regression Moderation Analysis for Social Problems and Temperament at $\mathrm{T} 1$

Table 14 - Social Problems as Mediating Factor for the Relationship

Between Temperament and a Diagnosis of MDD. 


\section{Introduction}

\section{Study Overview}

The objective of this study is to understand different pathways toward the emergence of Major Depressive Disorder (MDD) during adolescence. The investigation is guided by a broad conceptual model in which individual differences in temperament are predicted to increase risk for the emergence of specific symptoms, which in turn increase risk for the onset of MDD (see Figure 1). The key question addressed is whether there are alternative developmental pathways, related to the concepts of internalizing and externalizing symptom dimensions [1, 2], that arise from unique temperamental profiles, and that each predict unique variance in risk for depressive disorders. The next section, 'Adolescent Depression', will present a general perspective on adolescent development and its relationship to the development of depression to provide a contextual foundation for the specific areas of interest that were investigated. Next, relevant findings in the literature will be presented that explore the relationships among internalizing symptoms, externalizing symptoms, and dimensions of temperament as they relate to each other and depression.

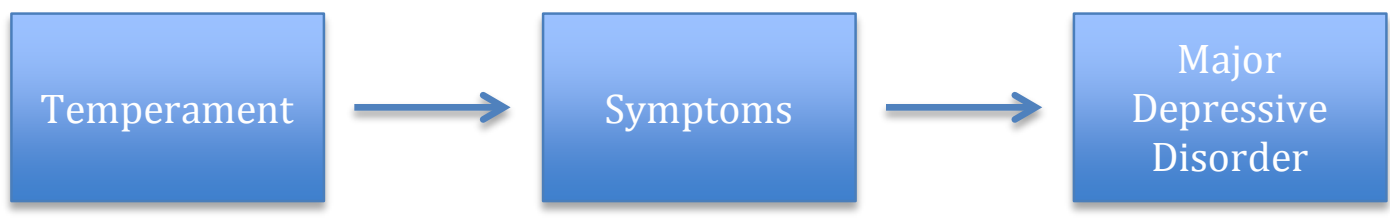

Figure 1 - Temperamental Pathway Toward Major Depressive Disorder 


\section{Adolescent Depression}

Depression is a leading cause of disability worldwide [3]. Individuals diagnosed with depression experience a worldview colored by extreme sadness, apathy, selfhatred, and feelings of helplessness, among other potentially debilitating and harmful symptoms. There is likely no singular path to a depressive episode because an incident of depression is thought to arise from complex interactions between environmental, biological, and psychosocial risk factors. A depressive episode carries risk for impaired cognitive functioning, social functioning, and physical health [4, 5]. Furthermore, a single depressive episode represents a strong risk factor for future depressive episodes and enduring reduced life satisfaction [6-8]. The incidence of depression begins to rise as individuals transition into early adolescence, with the prevalence of depressive disorders increasing from about $2.8 \%$ in children below age 13 to $5.6 \%$ in adolescents [9]. By age 18 almost 25\% of adolescents will have experienced a depressive episode [10-12], and youth who experience depression or dysthymia have been found to have higher rates of significant impairment compared to any other disorder [13]. Incidence of depression in adolescence generally peaks between the ages of 15 and 18 [14], and studies have shown that this peak can occur earlier (ages 13 and 15) in girls [15, 16].

The complexities experienced during the transition into adolescence may underlie the increased risk for the development of mental disorders during this period of life [17]. Adolescence is a marked period of rapid and significant changes within an individual, encompassing emotional, social, cognitive, and biological development [18]. It is a developmental period characterized by increases in incidence and severity of negative emotional states, increased sensitivity to peer-related social interactions, and 
greater cognitive engagement with more complex and long-term goals [19]. These changes have been hypothesized to increase vulnerability to emotional and behavioral dysregulation [20,21]. One of the fundamental changes that occur during adolescence is puberty. Changes during puberty affect both the biological development and social development of adolescents. Puberty has been shown to affect neurobiological mechanisms relating to emotional and social responsiveness, including an increased sensitivity to social status [22, 23]. Yet, the majority of individuals navigate adolescence without developing depressive disorders, suggesting that puberty may be a necessary but not sufficient risk factor for depression [24].

The social world that emerges during adolescence also becomes increasingly broad and complex as romantic relationships emerge, individual relationships become more trusting, and identity becomes associated with group membership [25-28]. The increased importance of social relationships coincides with a decrease in stability among these relationships; moreover, these changes occur within the context of increased sensitivity to peer rejection [19, 25, 29]. Some of this increased sensitivity may stem from the slow maturation of executive function (i.e., the process of deliberate self-regulation of thought, action, and emotion), which may potentiate the risk for distress and depression among adolescents [30]. Adolescence also marks a time of increased desire for autonomy and independent decision-making, which can lead to conflict within familial relationships where the power structure begins to be renegotiated between parent and child [31, 32]. The sharp increase of depression at the beginning of adolescence emphasizes the need to understand the relationship between adolescent development and depressive disorders [18]. For this reason, the following 
section will explore the literature on the etiological relationship among internalizing symptoms/disorders, externalizing symptoms/disorders, temperament, and risk for depression.

\section{The Etiology of Mental Health Disorders During Adolescence: Internalizing, Externalizing, and Temperamental}

Internalizing symptoms and disorders.

Depressive and anxious symptoms are two presentations of a broader dimension of internalizing symptoms, which also includes dimensions such as low self-esteem and neuroticism. Prospective longitudinal studies have elucidated a bidirectional relationship between anxious and depressive symptoms [33]. This bidirectional relationship has been observed during adolescence, such that individuals with increasing symptoms of anxiety tend to have subsequent increasing symptoms of depression across time, and vice versa [34, 35]. Moreover, these internalizing symptoms represent risk factors for the development of depressive and anxiety disorders during adolescence [1]. The co-occurrence of depressive and anxiety disorders is common, with estimates that around 59\% of depressed individuals have a lifetime diagnosis of an anxiety disorder, further emphasizing the commonalities between these disorders [36, 37]. Compared to experiencing depression alone, the experience of comorbid emotional distress is related to poorer treatment response and predicts a graver course of mental illness [38-40]. The current analysis will examine the impact of internalizing symptoms during early adolescence, categorized by depressive and anxious symptoms, as an early sign of adolescent-onset depression. However, internalizing symptoms represent only a 
piece of the puzzle. Factors such as externalizing problems also represent risk for depression and impact the expression of internalizing symptoms.

Externalizing symptoms and disorders: Comorbidity with internalizing symptoms and disorders.

Externalizing problems (i.e., aggressive behavior, conduct problems, and drug or alcohol dependence/abuse) are distinct from internalizing symptoms, and represent a unique risk factor and developmental pathway to the development of depression [41, 42]. Lewinsohn, Gotlib, and Seeley, using a one-year longitudinal study of older adolescents, found that externalizing problems did in fact represent a risk factor for the development of MDD [2]. For example, externalizing problems are related to peer rejection, which persists through adolescence [43] and often results in negative psychosocial outcomes [44, 45]. Aggression—including unregulated anger, disruptiveness, frustration, verbal acts, and physical aggression—is the most common characteristic of rejected youth [46]. Aggressive and peer-rejected youth are often themselves victims of aggression, which is attributed to retaliatory behavior from peers in response to the irritating and disruptive behavior of aggressive-rejected youth [46, 47]. Saluja and colleagues found that in early adolescence individuals who were regularly involved in bullying, either as a victim or perpetrator, were more than twice as likely to report depressive symptoms [48]. It is important to note that as individuals enter adolescence physical aggression typically decreases, because of improvements in emotion regulation and the development of social skills [49]; however, during this same adolescent transition instances of relational aggression increase (e.g. [50]). Relational 
aggression $^{1}$ is strongly associated with physical aggression [50], and is associated with other forms of antisocial behavior [51]. Relational aggression has been associated with social problems [52], peer rejection, internalizing and externalizing problems, and poor friendship quality [51, 53-57]. In addition, youth who are sullen and socially withdrawn also tend to elicit peer rejection, and being socially withdrawn can increase peer rejection as early-adolescents transition into middle- and late-adolescence $[58,59]$. Thus, rejected youth become easy targets for physical and relational aggression, which in turn can predict increases in internalizing symptoms [60, 61]. Externalizing symptoms impact the expression of internalizing symptoms, and the effect of externalizing events, such as aggression, on social relationships may be especially important during adolescence, because of the significance of social relationships during adolescent development.

The relationship between externalizing disorders and depression also reveals a significant dynamic among externalizing components, depression, and social relationships. Conduct Disorder (CD) and depression often co-occur, with observed rates ranging from 15-82\% among children and adolescence [62-69]. While this range is wide, it clearly suggests that the rates of depression among those with CD are greater than the general population. Depressed children with CD, compared to non-depressed children, have higher rates of substance use [70], anxiety disorders [71], social rejection [72], and suicide [73]. Empirically, within the literature, there have been mixed findings about the predictive relationship between externalizing disorders and risk for the development of depression [42, 74-76]. Loth, Drabick, Leibenluft, and Hulvershorn’s

\footnotetext{
${ }^{1}$ Relational aggression refers to a type of social aggression that is defined by behaviors of manipulation or exclusion intended to purposefully harm others [50].
} 
meta-analysis of childhood externalizing disorders used 10 studies that reported mixed results to examine if there was an overall effect of externalizing disorders on risk for depression [77]. They concluded that there was indeed a significant effect of externalizing disorders on the subsequent development of depression, although their results were limited by the fact that most studies used in their analysis did not control for comorbid childhood internalizing symptoms [77]. Externalizing symptoms and disorders appear to represent significant risk factors for depression, which lends support for an independent externalizing pathway of depression.

\section{Internalizing and externalizing pathways to Major Depressive Disorder}

Kendler, Gardner, and Prescott's studies on the risk factors for depression in women and men, respectively, provide support for the existence of distinct internalizing and externalizing pathways to the development of depressive disorders, including MDD $[41,78]$. They chart a third pathway related to adversity and interpersonal difficulties as a risk factor for depression. More recently, Kendler and Gardner replicated these findings, observing similar pathways within a mixed-gendered twin sample [79]. The internalizing pathway was characterized by genetic risk factors, neuroticism, early-onset anxiety disorders, low self-esteem, and history of depression. The externalizing pathway was characterized by genetic risk factors, conduct disorder, and substance misuse. These studies, however, have relied on retrospective analyses to examine risk factors, and therefore recall biases may have influenced their results. Additionally, their models assume a causal relationship between the predictor and dependent variables, when it is likely that there are also bidirectional relationships between variables. Thus, their model seems overly simplistic given the assumed linear and additive relationship 
between symptoms and risk for depression. Rather, the etiology of depression involves a complex and integrated relationship among biological, environmental, and psychological factors. While the work of Kendler, Gardner, and Prescott has demonstrated the existence of these pathways in their adult samples, the question remains if these same pathways can be demonstrated in a prospective analysis of adolescents [41, 78]. Another salient question about the development of MDD is which individual differences might predispose a person to take one path versus another. Temperament is a good factor to investigate because there is a clear relationship to both internalizing and externalizing symptoms and to risk for mood disorder.

\section{Temperament as a Risk Factor For Internalizing and Externalizing Symptoms}

Individual differences in temperament represent a related source of risk for mood disorders, specifically depression, and may be useful as an early predictor for internalizing and externalizing pathways and depression. Temperament is a construct that describes individual characteristics of infants, toddlers, children, and adolescents, such as outgoingness, irritability, and aggression. It is broadly defined as the differences in emotional, behavioral, and thought patterns that remain relatively stable through time and across situations and are genetically influenced [80-82]. Temperament is also modified by the environment and social experiences [80] and is believed to play an important role in personality and social development and psychological adjustment [83]. The tremendous change in motives and behaviors between infancy, childhood, adolescence, and adulthood creates challenges for the study of temperament [84]. 
Since the initial work of Thomas and Chess [85], models of temperament have included a wide range of traits [86]. However, the field has shifted focus toward the higher order traits of negative emotionality, positive emotionality, and effortful control, in part because these traits have been more clearly linked to neurobiological systems and have helped simplify comparisons across developmental periods [86]. Negative emotionality is reflective of high distress, sadness, and unpleasant environmental engagement, and is conceptually similar to neuroticism [84, 87]. Positive emotionality, or surgency, refers to an individual's ability to feel active, sociable, and enthusiastic, which reflects pleasurable engagement with the environment [80]. This construct closely parallels the personality factor of extraversion in adult models [88]. Effortful control, or constraint-attentional control, generally relates to the processes used to regulate behavioral and emotional responses, including inhibitory control (i.e., inhibiting specific behaviors if necessary) and attentional control (i.e., the ability to focus and shift attention) [84, 89, 90] (see Table 1 for a description of the various temperamental concepts and related terms).

Table 1 - Temperamental Dimensions and Related Concepts

\begin{tabular}{|l|l|}
\hline Temperament Dimension & Related Concepts \\
\hline Surgency (SUR) & Positive Emotionality (PEM) \\
& Positive Affect (PA) \\
& Extraversion \\
\hline Negative Emotionality (NEM) & Negative Affect (NA) \\
& Neuroticism \\
\hline Effortful Control (EC) & Constraint-Attentional Control \\
& Self-Regulation \\
\hline Affiliation (AF) & Desire for close relationships with others \\
\hline
\end{tabular}


The tripartite model of anxiety and depression has been used to explore the development of depressive disorders [91]. The model uses the temperamental dimensions of positive and negative affect, which are similar constructs to positive and negative emotionality, and are related to extraversion and neuroticism [91, 92]. These temperamental dimensions act as contributing factors to developing depressive symptoms [92]. Low levels of positive affect have been shown to uniquely predict depression, while higher levels of negative affect have been shown to be a common risk factor for both depression and anxiety [93]. The tripartite model also focuses on the dimension of effortful control.

Effortful control has been shown to moderate the association between negative affect, positive affect, and depression, such that low positive affect and high negative affect are associated with depression if effortful control is low [12]. In addition, positive affect, negative affect, and effortful control have been shown to be stable across time, and have been suggested as being useful for mapping different developmental pathways that lead to depression [94-97]. Temperament has also been shown to play a stronger role in adolescent-onset than adult-onset mood disorders, making it a pertinent factor for understanding the development of depression [96].

The dimensions of positive emotionality, negative emotionality, and effortful control have also been associated with externalizing symptoms and disorders. High levels of negative emotionality and low levels of effortful control have characterized Substance Use Disorder (SUDs) and antisocial disorders [98-101]. Eisenberg et al., [102] found that externalizing symptoms based on the Child Behavior Checklist (CBCL) [103] were also associated with high negative emotionality and low effortful 
control. Low levels of negative emotionality have correlated with antisocial disorders specifically characterized by aggression, rule-breaking, and lack of interpersonal empathy [95, 104]. However, Tacket and colleagues found relational aggression to be associated with higher levels of negative emotionality and lower levels of intra and interpersonal self-regulation, which is similar to effortful control, suggesting that the broader construct of externalizing problems is most strongly related to high, rather than low, negative emotionality [50].

\section{Temperament and Interpersonal Problems}

Interpersonal deficits and problems in relationships with family, peers and romantic partners are also key features in adolescent depression [105]. For example, Davila and colleagues examined a longitudinal sample of adolescents and found that poor interpersonal problem-solving skills predicted higher levels of interpersonal stress, which subsequently predicted elevated levels of depressive symptoms [106]. Not surprisingly, children with low positive emotionality, low effortful control, and high negative emotionality tend to have more interpersonal problems [107]. This evidence aligns with a growing body of literature that associates temperament and social competence, and that suggests that children with high negative emotionality and low positive emotionality do not have the ability to handle and adapt to challenging interpersonal interactions, fail to have appropriate responses in certain interpersonal situations, and elicit negative interpersonal responses from others [96]. Klein and colleagues suggest that this could create a vicious cycle that leads to developmental lags in learning social skills because these children have fewer opportunities to engage with 
peers and may avoid peer interactions [96]. In turn, this could lead to even greater interpersonal problems, and contribute to an increased risk for depression. Interpersonal problems are especially important during adolescence when peer and romantic relationships have greater significance.

\section{Conceptualization of Temperament in Adolescence}

Temperamental models have been identified specifically for early adolescents. The most useful model to date is the Early Adolescent Temperament QuestionnaireRevised (EATQ-R) which is a part of a larger set of comprehensive temperament models $[108,109]$. The EATQ-R is based on individual differences in reactivity and self-regulation among early adolescents [84]. Four broad temperamental factors emerged from Putnam, Ellis, and Rothbart's analysis of their adolescent-specific temperament model: effortful control, negative affectivity, surgency, and affiliation $[108,109]$. Effortful control and negative affect have been discussed in terms of their relationship to internalizing and externalizing problems, however, the dimensions of surgency and affiliation warrant more specific discussion. If an individual is considered high in surgency, they tend to experience high-intensity pleasure, low levels of shyness, and low levels of fear. Leve, Kim, and Pears found that higher levels of fear and shyness, which relate to low surgency, at age 5 uniquely predicted internalizing problems at 17 [110]. In addition, high levels of fear and shyness may act to inhibit social interactions, which gives individuals fewer opportunities for social learning, and may lead to greater social isolation. On the opposite end, very high levels of surgency, similar to the expression of personality by those with callous unemotional traits or 
antisocial tendencies, may result in greater externalizing problems [111, 112]. Affiliation refers to a desire for close relationships with others, independent of extraversion or shyness. This temperamental dimension plays a role in attachment, pair bonding, and sexual behaviors [113, 114]. Higher levels of affiliative need may make individuals more sensitive to interpersonal stressors, which in turn may lead to higher levels of internalizing symptoms [113, 115].

\section{Summary of Current Literature Review}

The literature provides support for both an internalizing and externalizing pathway to depression. Both internalizing symptoms and externalizing problems have been shown to affect social relationships during adolescence and significantly predict depressive symptoms and disorder (e.g. [1, 2, 106]). The existence of risk pathways using the constructs of internalizing and externalizing symptoms has not, to our knowledge, been examined in a prospective adolescent sample. The current review also reveals that multiple models of temperament have been shown to be a significant factor for predicting both symptoms of depression and depression itself (e.g. [93, 110]). However, many of the studies linking temperament to symptoms of depression have relied on cross-sectional analysis, which can create temporal and methodological confounds [86]. Additionally, some studies that have examined a longitudinal relationship between temperament and depression have used temperamental measures not designed specifically for adolescents (e.g. [93]). Temperament is a particularly important factor for studying the onset of adolescent mood disorders, given that it has been shown to be a stronger predictor in adolescents than in adulthood [116]. The 
current study begins to fill these gaps by examining the prospective relationship among adolescent-specific dimensions of temperament, symptoms of depression, and MDD.

\section{Hypotheses}

The goal of this study was to examine whether internalizing and externalizing symptoms at age 12 represent distinct pathways to developing clinical levels of depression over a six year follow up period, and also whether these symptoms represent a salient mechanism by which temperament is related to the outcome of MDD. We hypothesized that both internalizing and externalizing symptoms would predict unique pathways to MDD. We predicted that the internalizing pathway would be associated with higher levels of negative emotionality and affiliativeness, and lower levels of effortful control and surgency. We also predicted that the externalizing pathway would be associated with high levels of negative emotionality and low levels of effortful control (see Figure 2). Furthermore, given the importance of interpersonal processes, and relational aggression in particular, to development in early adolescence, we specifically examined whether interpersonal facets of externalizing behavior are salient mediators of the "externalizing” pathway to risk for MDD. 

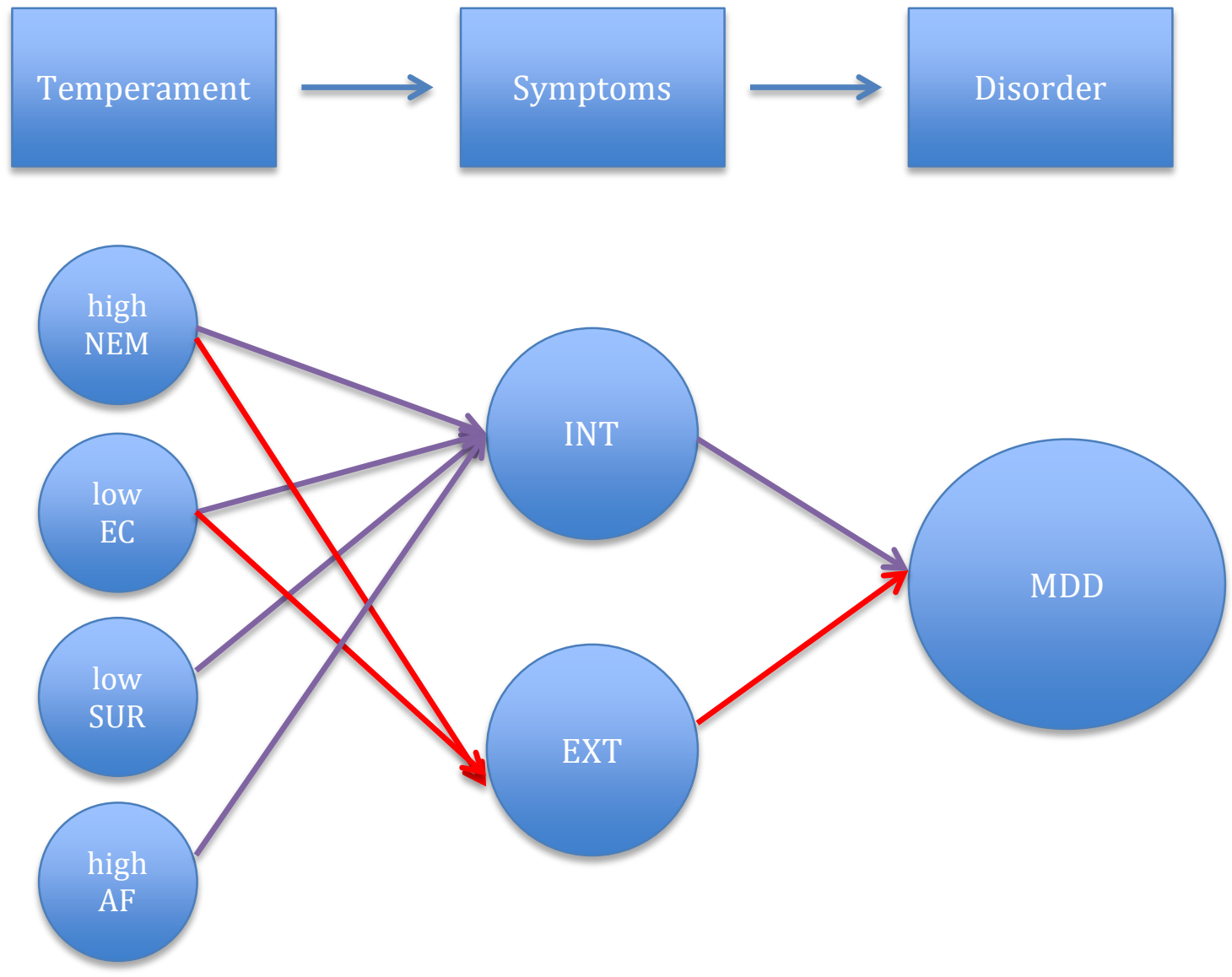

Figure 2 - Hypothesized Specific Pathways Toward MDD (Red arrows represent the hypothesized the externalizing pathway. Purple arrows represent the hypothesized internalizing pathway)

NEM = Negative Emotionality; EC = Effortful Control; SUR = Surgency; AF = Affiliation; INT = Internalizing Symptoms; EXT = Externalizing Symptoms; MDD = Major Depressive Disorder 


\section{Methods}

\section{Design}

This research was a part of the Orygen Adolescent Development Study (ADS), which was conducted in conjunction with Orygen Youth Health. The ADS is a prospective longitudinal study of youth in Melbourne, Australia, with the broader aim of examining biopsychosocial risk and resilience over the course of adolescence. Participants were comprehensively assessed using an extensive series of measures of brain structure, temperament, family processes, and psychopathology. Data were obtained from four phases of data collection over eight years. Participants were assessed at all four time points for Major Depressive Disorder (MDD) and anxiety disorders, among others, using a diagnostic interview.

\section{Participants}

A cohort of 2,453 individuals was involved in the initial in-school screening phase of the ADS. This original cohort was a representative sample of students in the sixth grade, aged 10-12 years old, from a random selection of schools across metropolitan Melbourne. To ensure a representative sample, the schools were defined within the stratified frame of Government, Catholic, and Independent Private schools. These three sectors represent $65 \%, 22.5 \%$, and $12.5 \%$ respectively of total school enrollment in Melbourne. Schools were selected at random with a probability proportional to their number of students within the sampling frame. Of the 175 schools invited to participate 97 (56\%) agreed to do so. Of the 2,453 children who participated 
in the initial screening 1,730 (71\%), 501 (20\%), and 222 (9\%) were from Government, Catholic, and Private schools, respectively. These proportions in the sampling population were not significantly different from those in the broader metropolitan area $\left(\chi^{2}(2)=0.81, \mathrm{p}>0.05\right)$

Children with a learning disability, obesity or growth failure, chronic medical or neurological illness, or a history of significant head injury with loss of consciousness for more than 5 minutes were excluded from this study. Participants were also excluded on the basis of a current or prior depressive, substance-use, or eating disorder.

The initial screening was conducted through an in-class administration of the Early Adolescent Temperament Questionnaire - Revised (EATQ-R) [109, 117]. The aim of the screening procedure was to produce a risk-enriched sample for the more intensive assessment phase. The school screening EATQ-R scores were used to select a sample that was representative of scores across the full range of temperament dimensions. To maximize variability in this smaller sample, all participants who were rated on the extreme ends of the temperamental domains were selected to continue participating in the study. Children with lower levels of risk were under-sampled. Selection was based on the reported scores from the negative emotionality and effortful control scales, given previous findings that these dimensions have a role in emotional and behavior problems. This resulted in a sample with a distribution of temporal risk that encompassed the full range associated with the larger screening sample, but remained normally distributed. Based on this initial screening a risk-enriched subsample of 415 participants was selected. 
Two hundred and forty-five families consented to participate in the first wave of home assessments, which occurred a mean of 9.91 months $(S D=3.10)$ after the initial school screening. At this time the participant's mean age was 12.49 years old (range 11.38-13.61). Of these participants, two had missing data for their depression symptoms at all four time points and were therefore excluded from the final analysis. The final sample for this analysis therefore consisted of 243 participants (121 males and 122 females). Figure 3 is a flow chart showing the numbers of participants assessed and the variables measured at each time point. There were no differences between adolescents who did not take part in the home assessment and those who did in the following areas: negative emotionality, $\mathrm{t}(407)=0.16, \mathrm{p}>.05$, effortful control, $\mathrm{t}(413)=-0.54, \mathrm{p}>.05$, sex, $\mathrm{X}^{2}(1, \mathrm{~N}=415)=0.34, \mathrm{p}>.05$, and socioeconomic status, $\mathrm{t}(405)=-1.00, \mathrm{p}>.05$. Socioeconomic status was based on an index of neighborhood social disadvantage (using participants' residential postcodes), which is calculated as a sum of 13 indicators, such as unemployment, income, criminal offences, child abuse, and early school leaving [118]. 


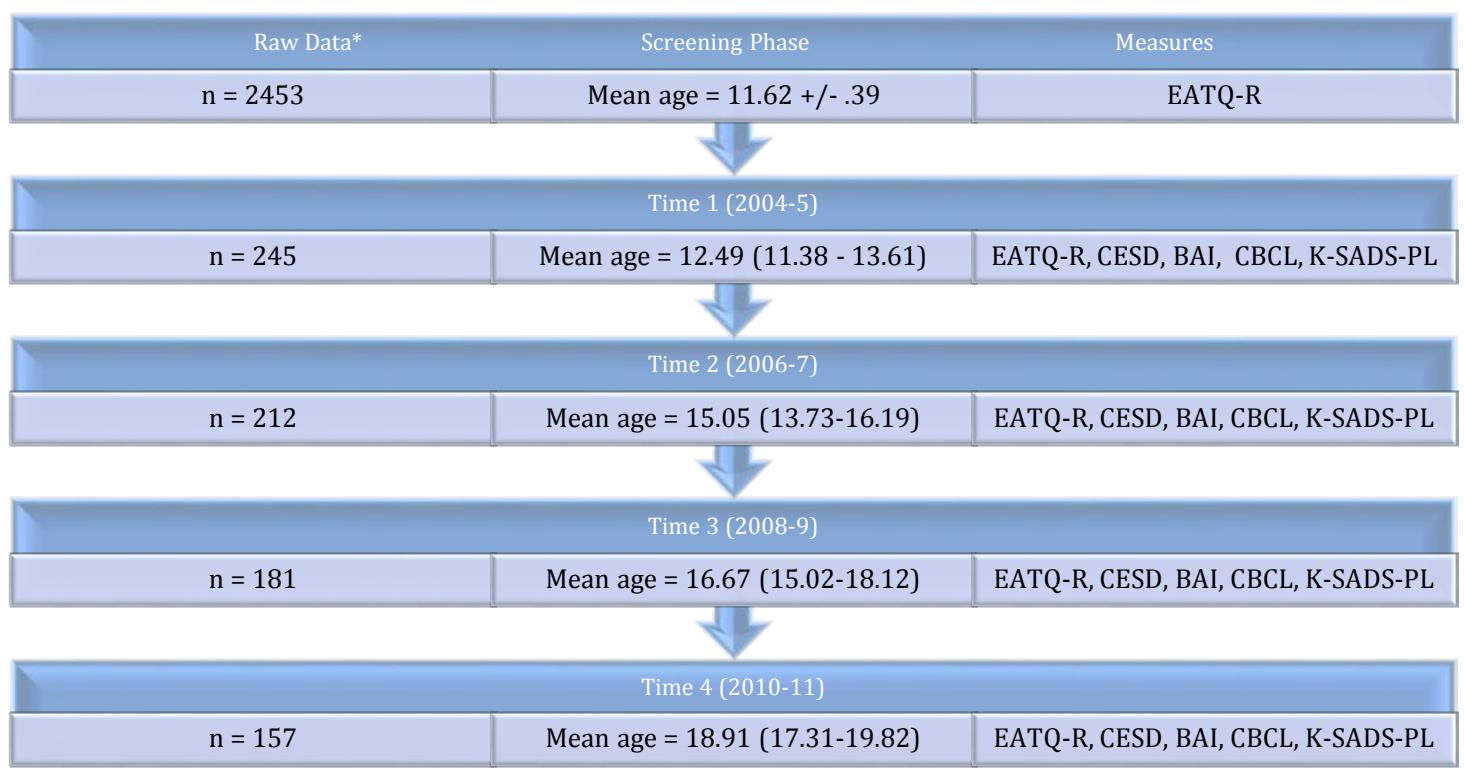

Figure 3 - Flow Chart of Data Collection by Wave

* Raw numbers prior to imputation of missing data

EATQ-R = Early Adolescent Temperament Questionnaire - Revised; CESD = Center for Epidemiological Studies Depression Scale; BAI = Beck Anxiety Inventory; CBCL = Child Behavior Checklist, Parent Version; K-SADS-PL = Schedule for Affective Disorders and Schizophrenia for School-Age Children, Present and Lifetime version

\section{Measures}

Early Adolescent Temperament Questionnaire - Revised (EATQ-R) [109, 117].

The EATQ-R is a 65-item questionnaire designed to measure temperamental characteristics, by specifically incorporating experiences common to adolescents. For each item respondents are asked to rate on a 5-point Likert scale the extent to which they agree or disagree with a particular statement. The EATQ-R includes 12 scales designed to measure aspects of self-regulation, reactivity, and emotionality. The scales are labeled activation control, affiliation, attention, fear, frustration, high intensity pleasure, inhibitory control, perceptual sensitivity, pleasure sensitivity, shyness, aggression, and depressive mood. The EATQ-R has good internal consistency, test- 
retest reliability and validity data. Exploratory factor analyses have revealed four factors: effortful control, surgency, affiliativeness, and negative emotionality. These four factors are used as variables in this analysis. The dimension of negative emotionality measures the experience of frustration and anger, effortful control is the ability to voluntarily regulate behavior and attention, surgency is a tendency to explore and seek novelty, and affiliativeness reflects pleasure sensitivity and a tendency to seek closeness with others. The child self-report form was used in this analysis. Adolescent self-reports of temperament were obtained at two time points (in-school screening and home assessment phases). The state-related variation in temperament was reduced by using the mean of the two measurements as the indictor of adolescent temperament in the present study.

\section{Center for Epidemiological Studies Depression Scale (CESD) [119]. The}

CESD is a widely used, 20-item self-report measure of depressive symptomatology that has respectable psychometric properties for use in both adolescent $[120,121]$ and adult populations. It examines cognitive, mood, appetitive, and motor aspects of depression. Items include statements regarding sadness, worthlessness, loss of interest, appetite, sleep, thinking, and fatigue. Respondents are asked how often each statement has been true for them in the past week, from "rarely" to "most of the time". Most of this adolescent sample reported low levels of depressive symptoms at Time 1 with 59\% reporting total scores of 0 to 10 .

Beck Anxiety Inventory (BAI) [122]. The BAI is a 21-item self-report questionnaire designed to assess the major cognitive, affective, and physiological 
symptoms associated with anxiety disorders and to discriminate anxiety from depression. It has been shown to be highly internally consistent and acceptably reliable, and to have better convergent and divergent validity than the alternative State-Trait Anxiety Inventory [123].

Child Behavior Checklist, Parent Version (CBCL) [103]. The CBCL is a 45item questionnaire containing only the externalizing scale. The CBCL is a widely used screening tool for youth behavior problems. The problem scales contain items that are rated by parents (CBCL) or youth (Youth Self-Report; YSR). Based on factor analytic results, items were grouped into syndrome scales (e.g., attention problems), and broader factors reflecting internalizing and externalizing symptoms. Only externalizing symptom factor was analyzed in this study. The CBCL and YSR have very good internal, test-retest, and inter-parent reliabilities, and discriminate between clinicreferred and other children.

\section{Schedule for Affective Disorders and Schizophrenia for School-Age Children,} Present and Lifetime version (K-SADS-PL) [124]. The K-SADS-PL is a semistructured diagnostic interview assessing current and lifetime symptoms and diagnoses of Axis I disorders in youths aged 6 to 18 years. The K-SADS-PL has demonstrated good inter-rater agreement, test-retest reliability, and diagnostic validity [124]. Recordings of $20 \%$ to $25 \%$ of all K-SADS-PL interviews at each of the four ADS waves of data collection were rerated by a second coder. The kappa coefficient for symptom-level agreement was 0.80 at $\mathrm{T} 1,0.78$ at $\mathrm{T} 2,0.86$ at $\mathrm{T} 3$, and 0.81 at $\mathrm{T} 4$, which suggests excellent inter-rater reliability across diagnoses at all time points [124]. 


\section{Results}

\section{Data Screening and Missing Data}

The data were screened for outliers, but no outliers of enough significance existed to warrant adjusting the data. We thus took a conservative approach and left the data unadjusted. However, when conducting longitudinal studies missing data is common. An expectation-maximization imputation was used to impute missing data to obtain the best possible representation of the sample population [125].

\section{Descriptive Statistics}

Major Depressive Disorder was diagnosed in 47 of the 245 adolescents. Among female adolescents, 32 of 122 were diagnosed with MDD during the follow up period, and among males, 15 of 121 were diagnosed. Table 2 summarizes the descriptive statistics of the internalizing and externalizing symptom questionnaires completed at T1. Table 3 summarizes the descriptive statistics of temperament, measured by the EATQ-R, at T1. 
Table 2 - Descriptive Statistics Symptom Questionnaires T1

\begin{tabular}{|l|l|l|r|r|r|}
\hline & $\mathrm{N}$ & Min & \multicolumn{1}{l|}{ Max } & \multicolumn{1}{l|}{ Mean } & \multicolumn{1}{c|}{ Std. Dev. } \\
\hline BAI & 237 & .00 & 44.21 & 8.54 & 9.1 \\
\hline CESD & 227 & .00 & 55 & 11.44 & 9.38 \\
\hline CBCL & 230 & .00 & 73 & 15.21 & 12.95 \\
\hline CBCL Social Problems & 230 & .00 & 12 & 2.34 & 2.56 \\
\hline CBCL Attention Problems & 230 & .00 & 15 & 3.50 & 3.35 \\
\hline CBCL Delinquent Behavior & 230 & .00 & 17 & 2.07 & 2.53 \\
\hline CBCL Aggressive Behavior & 230 & .00 & 33 & 7.71 & 7.01 \\
\hline
\end{tabular}

Table 3 - Descriptive Statistics Temperament T1

\begin{tabular}{|l|l|r|r|r|r|}
\hline & \multicolumn{1}{|c|}{$\mathrm{N}$} & \multicolumn{1}{l|}{ Min } & \multicolumn{1}{l|}{ Max } & \multicolumn{1}{l|}{ Mean } & \multicolumn{1}{c|}{ Std. Dev. } \\
\hline Surgency & 228 & 1.71 & 5.00 & 3.44 & .68 \\
\hline Affiliation & 238 & 1.54 & 4.92 & 3.37 & .57 \\
\hline Effortful Control & 228 & 1.85 & 4.86 & 3.52 & .63 \\
\hline Negative Emotionality & 227 & 1.14 & 5.00 & 3.10 & .78 \\
\hline
\end{tabular}

\section{Inter-correlations and Data Reduction}

Table 4 presents correlations for symptom questionnaires and measures of temperament. Anxiety had significant medium correlations with the temperament dimensions of effortful control and negative affect, while depression symptoms had strong significant correlations with effortful control and negative affect. There were strong positive correlations between symptoms of anxiety and depression and among the externalizing symptoms measured by the CBCL. Less robust but significant correlations were found between internalizing symptoms and externalizing symptoms. A principal components factor analysis was conducted to isolate and extract the significant predictive factors from the data set, given the strong correlations between 
internalizing symptoms and among externalizing symptoms. Two significant factors emerged with Eigen values above 1, and combined, they explained $74.69 \%$ of the variance in responses. In Table 5 component 1 represents externalizing symptoms and component 2 represents internalizing symptoms. Next, a varimax rotation was applied to the factor analysis in order to simplify the columns of the component matrix into clustered variables, and to make the interpretation of the externalizing and internalizing factors (which were found in the factor analysis) relevant. As expected, anxiety and depression scales clustered under the internalizing factor and the sub-categories of the CBCL clustered under the externalizing factor (Table 6). 


\begin{tabular}{|c|c|c|c|c|c|c|c|c|c|c|c|}
\hline$\dot{0}$ & & & & & & & & & & & - \\
\hline कं & & & & & & & & & & -1 & 蒾 \\
\hline$\infty$ & & & & & & & & & $\neg$ & $\stackrel{*}{\exists}$ & $\begin{array}{l}0 \\
0\end{array}$ \\
\hline $\boldsymbol{N}^{\circ}$ & & & & & & & & $\neg$ & $\underset{i}{\stackrel{Y}{\Xi}}$ & $\stackrel{*}{\stackrel{*}{*}}$ & * \\
\hline$\dot{0}$ & & & & & & & -1 & $\stackrel{*}{{ }^{*}}$ & 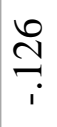 & صִ & 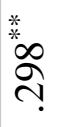 \\
\hline$\dot{~}$ & & & & & & -1 & $\stackrel{\text { * }}{\stackrel{*}{ }}$ & $\stackrel{\text { 옹 }}{\stackrel{0}{0}}$ & $\begin{array}{l}\infty \\
\infty \\
0 \\
0 \\
i\end{array}$ & 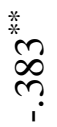 & 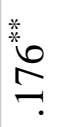 \\
\hline$\dot{\nabla}$ & & & & & -1 & 荬 & 蒾 & 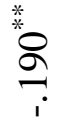 & 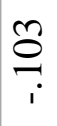 & 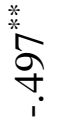 & $\begin{array}{l}\text { *.* } \\
\text { ํํำ }\end{array}$ \\
\hline$\dot{m}$ & & & & $\neg$ & $\stackrel{*}{*}$ & $\stackrel{*}{*}$ & $\begin{array}{l}\text { * } \\
\stackrel{*}{n} \\
\text { กิ }\end{array}$ & 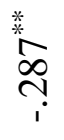 & $\underset{i}{\stackrel{\Xi}{\Xi}}$ & 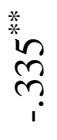 & 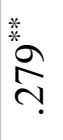 \\
\hline$\dot{m}$ & & & -1 & 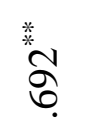 & $\stackrel{*}{*} \underset{\infty}{\infty}$ & $\begin{array}{l}* \\
\stackrel{*}{*} \\
\stackrel{2}{\infty} \\
\infty\end{array}$ & $\stackrel{*}{*}$ & $\frac{*}{*}$ & $\stackrel{m}{\underset{7}{7}}$ & $\begin{array}{l}\stackrel{*}{*} \\
\stackrel{*}{ت}\end{array}$ & 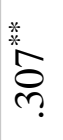 \\
\hline i & & $\neg$ & 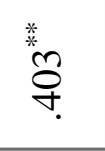 & 蒾 & $\begin{array}{l}\text { * } \\
\stackrel{*}{*} \\
\text { m }\end{array}$ & 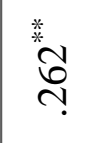 & $\begin{array}{l}\text { * } \\
\text { مె } \\
\text { m. }\end{array}$ & $\stackrel{\text { * }}{\stackrel{*}{m}} \underset{\sim}{m}$ & है. & $\stackrel{*}{*}$ & $\stackrel{*}{*}$ \\
\hline$-\dot{ }$ & $\neg$ & $\stackrel{\text { * }}{\stackrel{*}{\circ}}$ & 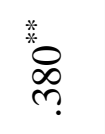 & 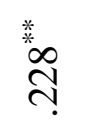 & 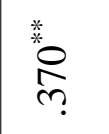 & 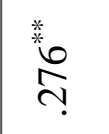 & $\begin{array}{l}\text { 类 } \\
\stackrel{1}{\mathrm{n}} \\
\end{array}$ & $\stackrel{\text { * }}{\stackrel{*}{\sim}} \underset{i}{+}$ & $\begin{array}{l}\infty \\
\infty \\
0\end{array}$ & 蒾 & $\begin{array}{l}\text { * } \\
\text { 。 } \\
\stackrel{5}{+}\end{array}$ \\
\hline & 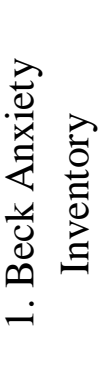 & 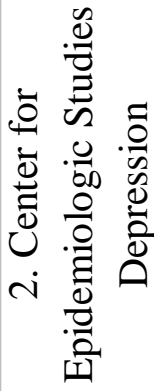 & 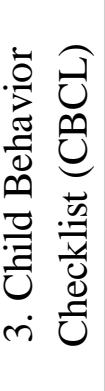 & 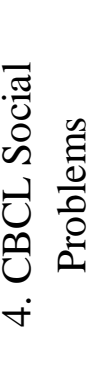 & 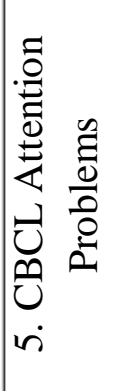 & 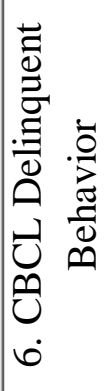 & 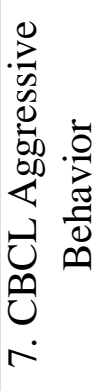 & 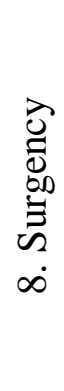 & 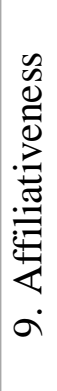 & 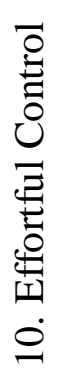 & 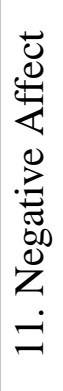 \\
\hline
\end{tabular}




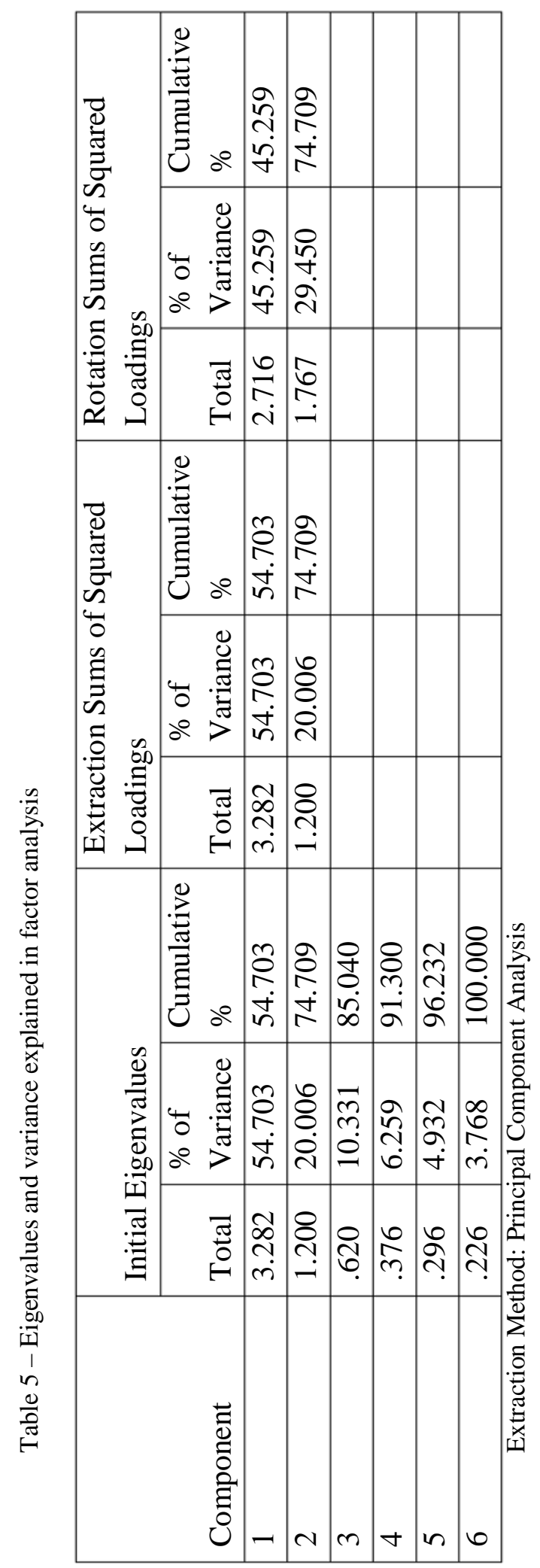


Table 6 - Rotated Component Matrix ${ }^{\mathrm{a}}$

\begin{tabular}{|l|l|l|}
\hline \multirow{2}{*}{} & \multicolumn{2}{|c|}{ Component } \\
\cline { 2 - 3 } & Externalizing (1) & Internalizing (2) \\
\hline Beck Anxiety Inventory T1 & .179 & .905 \\
\hline $\begin{array}{l}\text { Center for Epidemiologic Studies } \\
\text { Depression T1 }\end{array}$ & .200 & .898 \\
\hline CBCL Social Problems T1 & .746 & .129 \\
\hline CBCL Attention Problems T1 & .831 & .225 \\
\hline CBCL Delinquent Behavior T1 & .820 & .113 \\
\hline CBCL Aggressive Behavior T1 & .852 & .246 \\
\hline
\end{tabular}

CBCL = Child Behavior Checklist, Parent Version; Extraction Method: Principal

Component Analysis; Rotation Method: Varimax with Kaiser Normalization;

a. Rotation converged in 3 iterations

\section{Between Group Differences}

A series of t-tests were conducted to examine mean differences between youth diagnosed with MDD and those not diagnosed, and to examine sex differences within the sample. Those diagnosed with MDD had significantly higher reported scores on the BAI, CESD, CBCL Social Problems, and combined internalizing factor values than those not diagnosed with MDD (see Table 7). There were also sex differences among the measures. Females had significantly higher levels of MDD and significantly lower levels of reported CBCL social problems, attention problems, and delinquent behavior compared to males (see Table 8). 


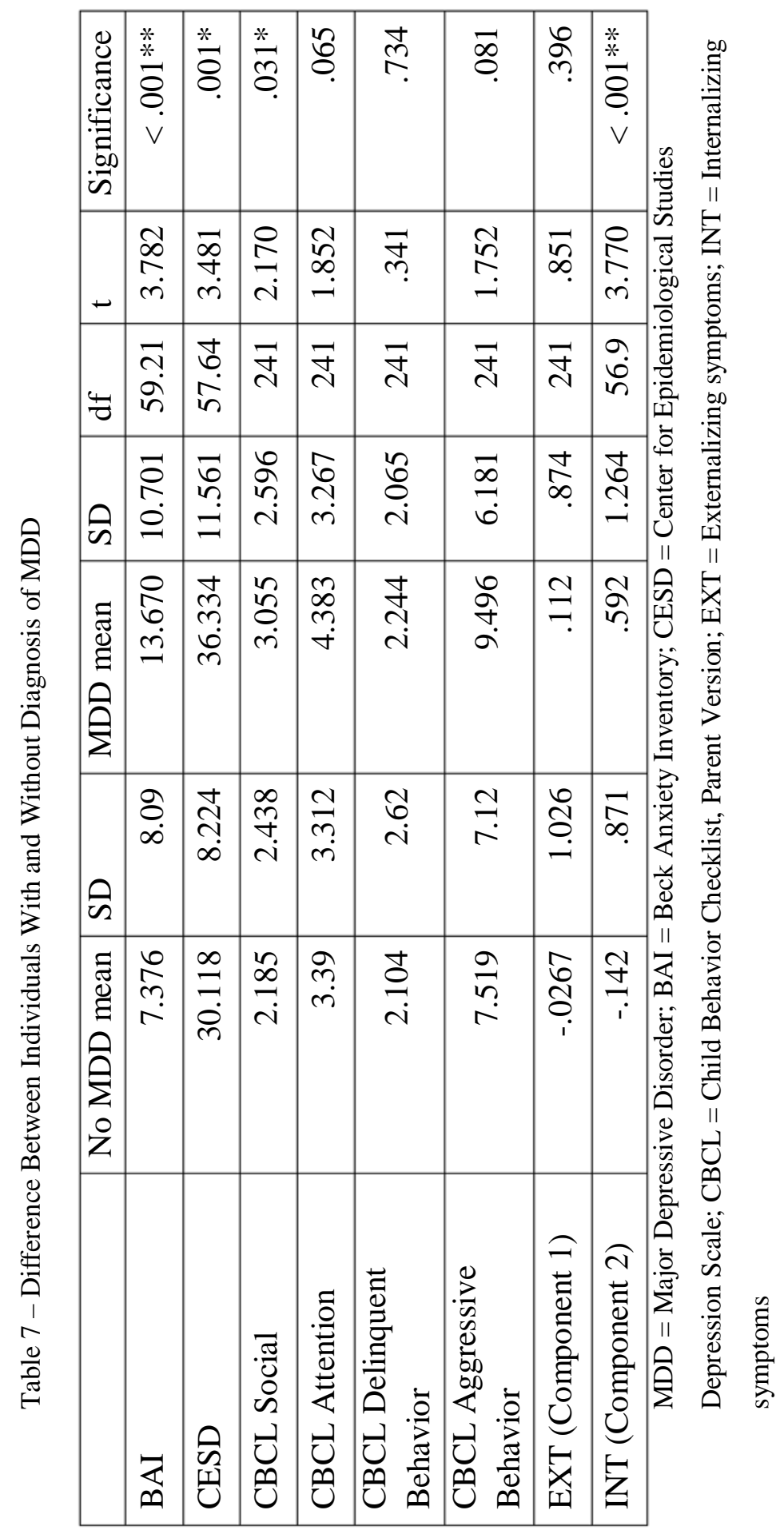




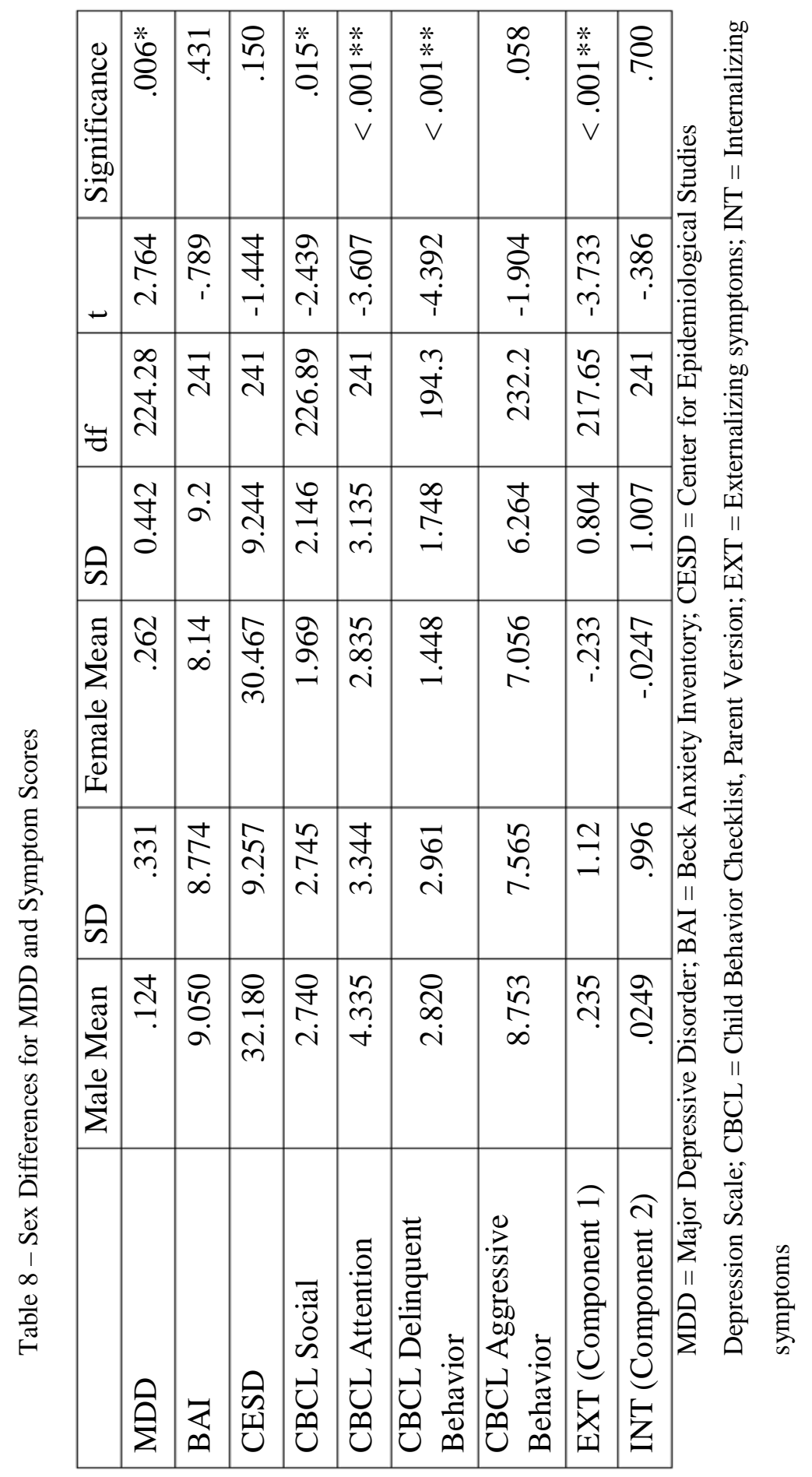


Table 9 - Temperamental Differences Between Individuals With and Without MDD

\begin{tabular}{|l|r|r|r|r|r|r|r|}
\hline & No MDD mean & SD & \multicolumn{1}{l|}{$\begin{array}{l}\text { MDD } \\
\text { mean }\end{array}$} & \multicolumn{1}{l|}{ SD } & df & t & Significance \\
\hline NEM & 3.141 & .784 & 3.465 & .670 & 241 & 2.613 & $.010^{*}$ \\
\hline SUR & 3.442 & .639 & 3.204 & .743 & 241 & -2.221 & $.027^{*}$ \\
\hline AF & 3.343 & .542 & 3.566 & .542 & 241 & 2.533 & $.012^{*}$ \\
\hline EC & 3.477 & .603 & 3.332 & .647 & 241 & -1.462 & .145 \\
\hline
\end{tabular}

All Temperament Variables Averaged Between T0 and T1. NEM = Negative

Emotionality; SUR = Surgency; EC = Effortful Control; AF = Affiliation;

$*$ significant at $\mathrm{p}=.05$

Table 10 - Temperamental Differences Between Sexes

\begin{tabular}{|l|r|r|r|l|r|r|r|}
\hline & Male Mean & SD & Female Mean & SD & df & t & Significance \\
\hline NEM & 3.293 & .661 & 3.114 & .863 & 223.52 & -1.811 & .072 \\
\hline SUR & 3.412 & .659 & 3.379 & .674 & 241 & -.387 & .699 \\
\hline AF & 3.276 & .550 & 3.496 & .526 & 241 & 3.175 & $.002^{*}$ \\
\hline EC & 3.327 & .594 & 3.569 & .610 & 241 & 3.113 & $.002^{*}$ \\
\hline
\end{tabular}

All Temperament Variables Averaged Between T0 and T1. NEM = Negative

Emotionality; SUR = Surgency; EC = Effortful Control; AF = Affiliation;

$*$ significant at $\mathrm{p}=.05$

\section{Prediction of Onset of Major Depressive Disorder}

Next, a series of logistic regressions were conducted using five different models to examine the predictive value of internalizing and externalizing factors on the development of MDD, while controlling for sex. Independent variables were entered as sets for logistic regression analysis. Model 1 was significant overall, $X^{2}(3, N=243)=$ 29.095, $p<.001$. However, the result of using internalizing and externalizing symptoms as predictors in Model 1 revealed that externalizing symptoms did not uniquely predict 
MDD diagnosis, while internalizing symptoms did (see Table 11). Post-hoc analyses were conducted to examine the sub-categories of the externalizing symptoms in relation to internalizing symptoms (see Models 2-5). All regression models significantly predicted an outcome of MDD with moderate to large effect sizes. Only social problems predicted unique variance above and beyond that of internalizing symptoms (Model 2). Next, logistic regression was applied to examine if temperament moderated the relationship between both internalizing symptoms and social problem symptoms in predicting the development of depression. No significant relationships were found (see Tables 12 and 13). 
Table 11 - Summary of a Series of Logistic Regression Analyses (controlling for sex), with Internalizing Symptoms and Respective Externalizing Symptoms at T1 Predicting Diagnosis of Major Depressive Disorder

\begin{tabular}{|c|c|c|c|c|c|c|c|}
\hline DV & Model & $\begin{array}{l}\text { Predictors in } \\
\text { Model }\end{array}$ & B & $\begin{array}{l}\text { Standard } \\
\text { Error }\end{array}$ & Wald & $\mathrm{df}$ & Significance \\
\hline \multirow{15}{*}{$\begin{array}{l}\text { Major } \\
\text { Depressive } \\
\text { Disorder }\end{array}$} & \multirow{3}{*}{$\begin{array}{c}\text { Model } \\
1\end{array}$} & Sex & 1.172 & .378 & 9.604 & 1 & $.002 *$ \\
\hline & & $\begin{array}{l}\text { Internalizing } \\
\text { Symptoms }\end{array}$ & .681 & .163 & 17.484 & 1 & $<.001^{* *}$ \\
\hline & & $\begin{array}{l}\text { Externalizing } \\
\text { Symptoms }\end{array}$ & .257 & .171 & 2.270 & 1 & .132 \\
\hline & \multirow{3}{*}{$\begin{array}{c}\text { Model } \\
2\end{array}$} & Sex & 1.193 & .379 & 9.911 & 1 & $.002 *$ \\
\hline & & $\begin{array}{l}\text { Internalizing } \\
\text { Symptoms }\end{array}$ & .651 & .164. & 15.686 & 1 & $<.001^{* *}$ \\
\hline & & $\begin{array}{l}\text { Social } \\
\text { Problems }\end{array}$ & .143 & .067 & 4.568 & 1 & $.033 *$ \\
\hline & \multirow{3}{*}{$\begin{array}{c}\text { Model } \\
3\end{array}$} & Sex & 1.155 & .375 & 9.478 & 1 & $.002 *$ \\
\hline & & $\begin{array}{l}\text { Internalizing } \\
\text { Symptoms }\end{array}$ & .621 & .166 & 13.908 & 1 & $<.001^{* *}$ \\
\hline & & $\begin{array}{l}\text { Attentional } \\
\text { Problems }\end{array}$ & .075 & .053 & 2.053 & 1 & .152 \\
\hline & \multirow{3}{*}{$\begin{array}{c}\text { Model } \\
4\end{array}$} & Sex & 1.098 & .378 & 8.438 & 1 & $.004^{*}$ \\
\hline & & $\begin{array}{l}\text { Internalizing } \\
\text { Symptoms }\end{array}$ & .671 & .165 & 16.571 & 1 & $<.001^{* *}$ \\
\hline & & $\begin{array}{l}\text { Delinquent } \\
\text { Behavior }\end{array}$ & .033 & .074 & .193 & 1 & .660 \\
\hline & \multirow{3}{*}{$\begin{array}{c}\text { Model } \\
5\end{array}$} & Sex & 1.090 & .369 & 8.735 & 1 & $.003 *$ \\
\hline & & $\begin{array}{l}\text { Internalizing } \\
\text { Symptoms }\end{array}$ & 6.641 & .168 & 14.630 & 1 & $<.001^{* *}$ \\
\hline & & $\begin{array}{l}\text { Aggressive } \\
\text { Behavior }\end{array}$ & .024 & .025 & .896 & 1 & .344 \\
\hline
\end{tabular}

* Significant at .05 level ** Significant at .001 level 
Table 12 - Summary of Logistic Regression Moderation Analysis for Internalizing

Symptoms and Temperament at T1

\begin{tabular}{|l|l|l|l|r|r|r|}
\hline DV & $\begin{array}{l}\text { Moderation } \\
\text { Factors }\end{array}$ & B & \multicolumn{1}{l|}{$\begin{array}{l}\text { Standard } \\
\text { Error }\end{array}$} & Wald & df & \multicolumn{1}{l|}{ Significance } \\
\hline \multirow{3}{*}{$\begin{array}{l}\text { Major } \\
\text { Depressive } \\
\text { Disorder }\end{array}$} & INT by NEM & -.229 & .228 & 1.004 & 1 & .316 \\
\cline { 2 - 7 } & INT by SUR & .030 & .266 & .013 & 1 & .909 \\
\cline { 2 - 7 } & INT by EC & .201 & .243 & .686 & 1 & .408 \\
\cline { 2 - 7 } & INT by AF & .339 & .351 & .933 & 1 & .334 \\
\hline
\end{tabular}

INT = Internalizing Symptoms; NEM = Negative Emotionality; SUR = Surgency; EC =

Effortful Control; AF = Affiliation

Table 13 - Summary of Logistic Regression Moderation Analysis for Social Problems and Temperament at $\mathrm{T} 1$

\begin{tabular}{|l|l|l|r|r|r|r|}
\hline DV & $\begin{array}{l}\text { Moderation } \\
\text { Factors }\end{array}$ & B & $\begin{array}{l}\text { Standard } \\
\text { Error }\end{array}$ & Wald & df & \multicolumn{1}{l|}{ Significance } \\
\hline \multirow{3}{*}{$\begin{array}{l}\text { Major } \\
\text { Depressive } \\
\text { Disorder }\end{array}$} & SOC by NEM & -.090 & .085 & 1.118 & 1 & .290 \\
\cline { 2 - 7 } & SOC by SUR & -.113 & .097 & 1.339 & 1 & .247 \\
\cline { 2 - 7 } & SOC by EC & -.049 & .109 & .205 & 1 & .650 \\
\cline { 2 - 7 } & SOC by AF & .202 & .134 & 2.266 & 1 & .132 \\
\hline
\end{tabular}

SOC = CBCL Social Problems; NEM = Negative Emotionality; SUR = Surgency; EC =

Effortful Control; AF = Affiliation

\section{Mediation Analyses}

We next conducted a series of mediation analyses. Mediation analysis was conducted using a bootstrapping approach, which does not violate any assumptions of normality within the data [126]. When using this approach the direct pathway between 
temperament and MDD does not need a significant correlation because the analysis directly tests the significance of the indirect pathway. Temperament scores were averaged between $\mathrm{T} 0$ and $\mathrm{T} 1$ in order to establish temporal precedence to the internalizing symptoms and social problem symptoms, and to account for any day-today influence that could create variation between scores. We first examined the relationship among temperament, internalizing symptoms, and MDD. Internalizing symptoms at T1 significantly mediated the relationship between all measures of temperament and a diagnosis of MDD (Figures 4-7). Next, we examined whether social problems at T1 mediated the relationship between temperament and a subsequent diagnosis of MDD. Social problems significantly mediated the relationship between effortful control and a diagnosis of MDD (Figure 8). The temperamental dimensions negative emotionality, surgency, and affiliation did not significantly mediate this relationship (Table 14). 


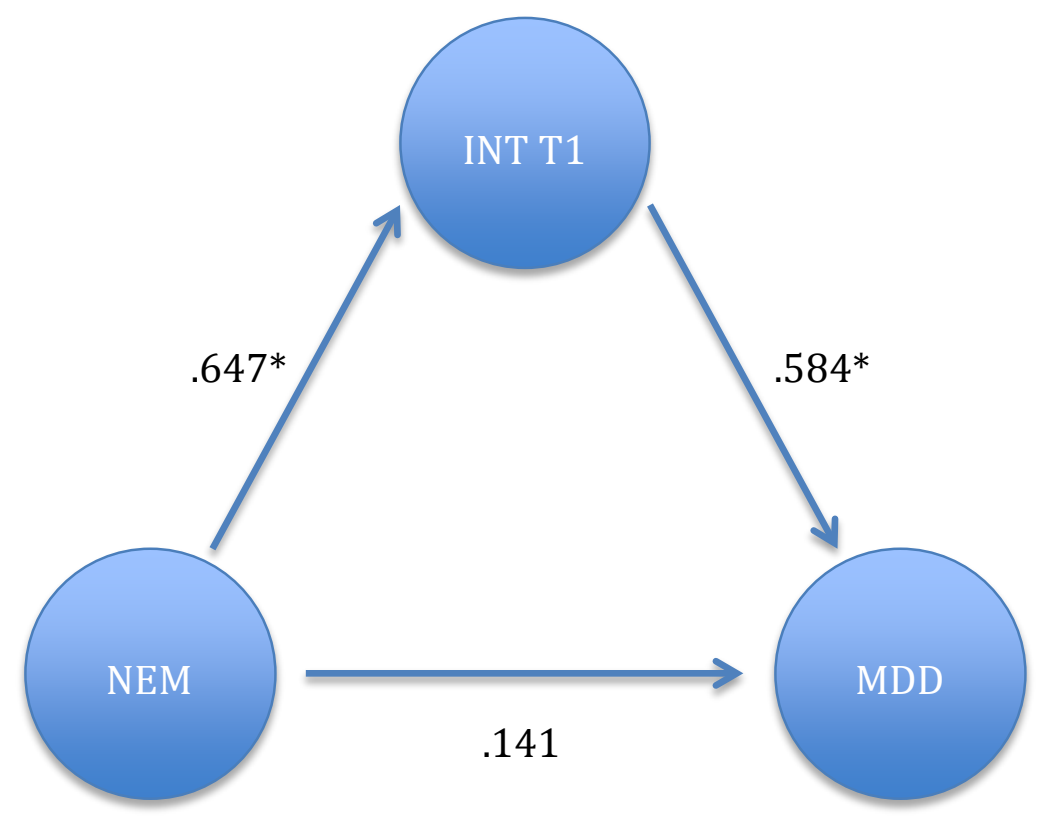

Figure 4 - Mediation among negative emotionality (NEM), internalizing symptoms (INT), and Major Depressive Disorder (MDD)

Internalizing symptoms at $\mathrm{T} 1$ significantly mediated the relationship between negative emotionality and a diagnosis of MDD. The standardized indirect effect of the internalizing symptom pathway was .378 (95\% CI $=.13$ to .674). Higher levels of negative emotionality predicted higher levels of internalizing symptoms, which in turn predicted a diagnosis of MDD. 


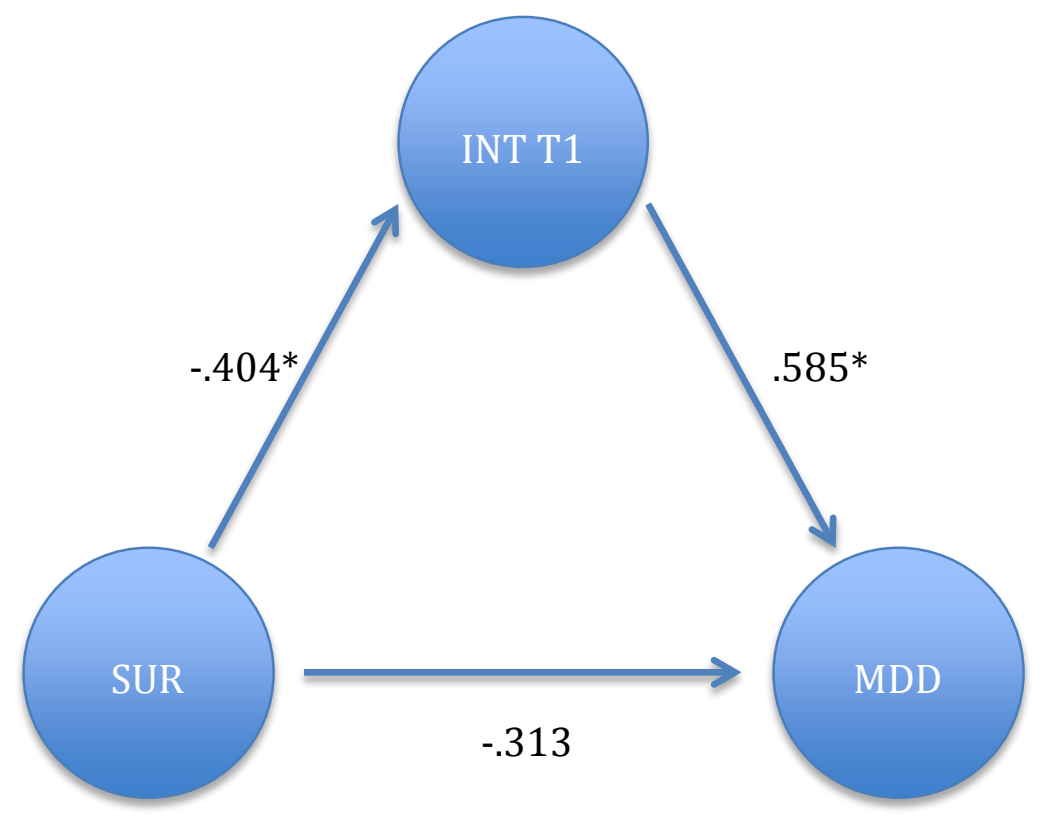

Figure 5 - Mediation among surgency (SUR), internalizing symptoms (INT), and Major Depressive Disorder (MDD)

Internalizing symptoms at T1 significantly mediated the relationship between surgency and a diagnosis of MDD. The standardized indirect effect of the internalizing symptom pathway was -.236 (95\% CI $=-.431$ to -.093$)$. Lower levels of surgency predicted higher levels of internalizing symptoms, which in turn predicted a diagnosis of MDD. 


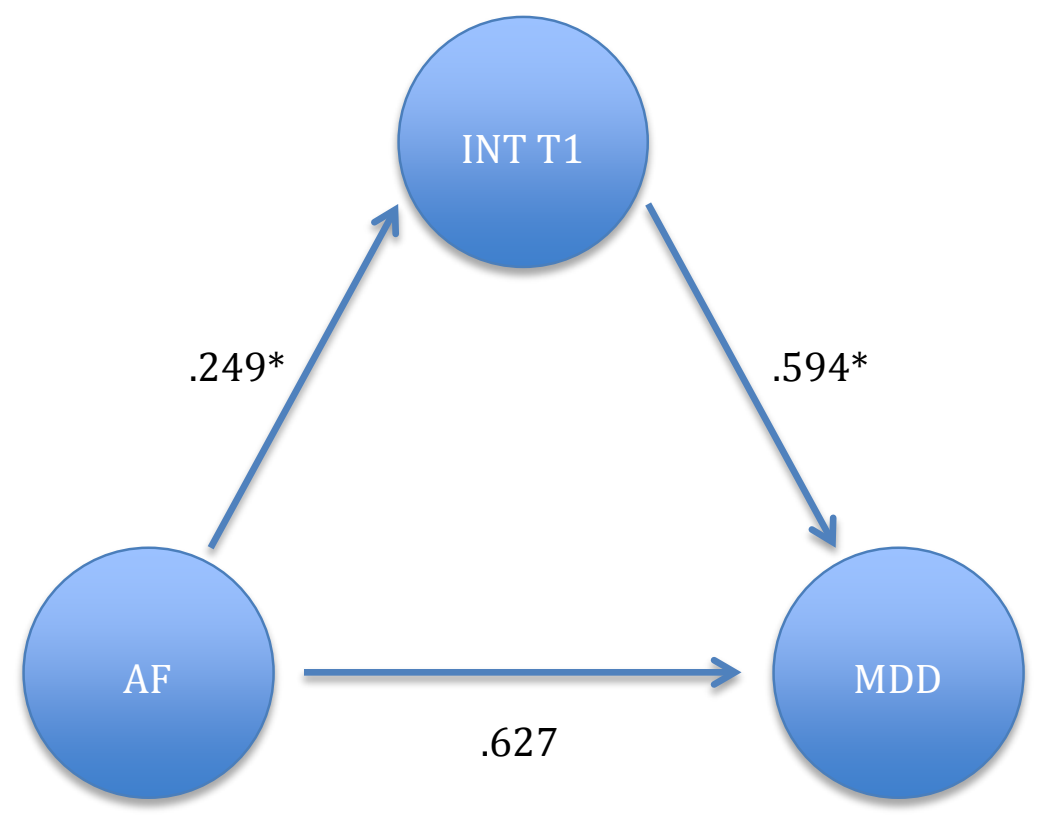

Figure 6 - Mediation among affiliativeness (AF), internalizing symptoms (INT), and Major Depressive Disorder (MDD)

Internalizing symptoms at $\mathrm{T} 1$ significantly mediated the relationship between affiliativeness and a diagnosis of MDD. The standardized indirect effect of the internalizing symptom pathway was .148 (95\% CI $=.017$ to .367$)$. Higher levels of affiliativeness predicted higher levels of internalizing symptoms, which in turn predicted a diagnosis of MDD. 


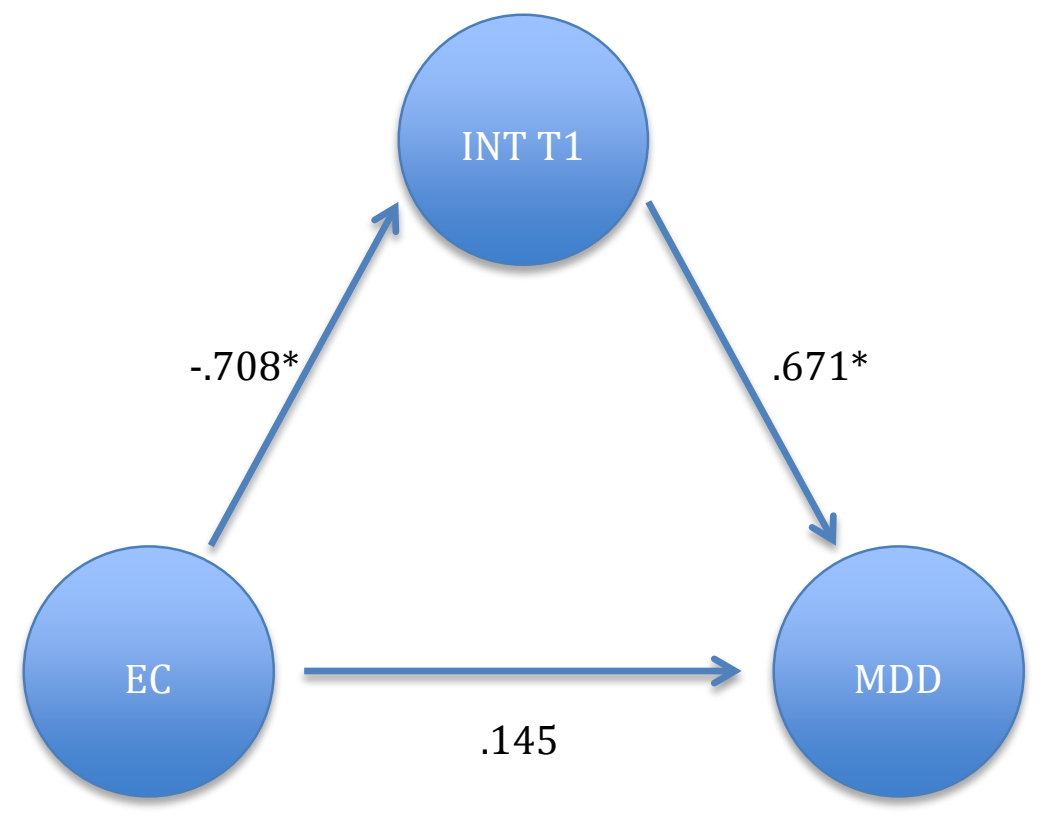

Figure 7 - Mediation among effortful control (EC), internalizing symptoms (INT), and Major Depressive Disorder (MDD)

Internalizing symptoms at $\mathrm{T} 1$ significantly mediated the relationship between effortful control and a diagnosis of MDD. The standardized indirect effect of the internalizing symptom pathway was -.475 (95\% CI $=-.794$ to -.199 ). Lower levels of effortful control predicted higher levels of internalizing symptoms, which in turn predicted a diagnosis of MDD. 


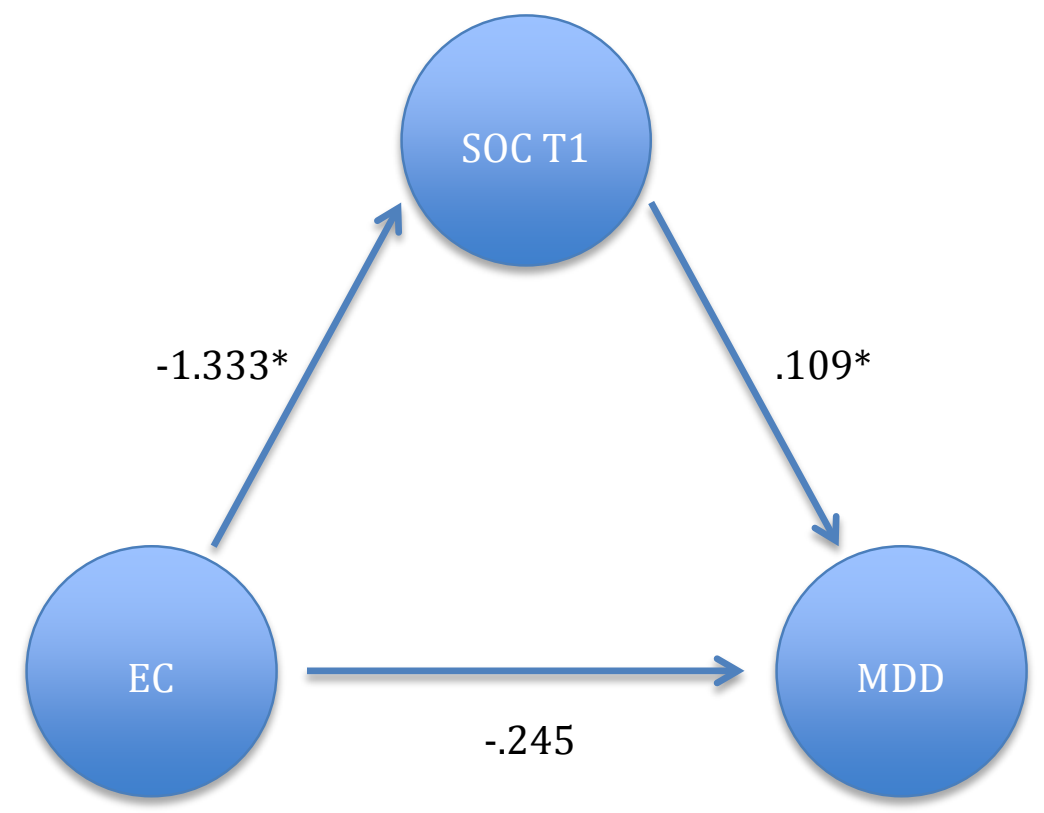

Figure 8 - Mediation among effortful control (EC), social problems (SOC), and Major Depressive Disorder (MDD)

Social problems at T1 significantly mediated the relationship between effortful control and a diagnosis of MDD. The standardized indirect effect of the social problem pathway was -.145 (95\% CI = -.337 to -.008). Lower levels of effortful control predicted higher levels of social problems, which in turn predicted a diagnosis of MDD. 
Table 14 - Social Problems as Mediating Factor for the Relationship Between Temperament and a Diagnosis of MDD.

\begin{tabular}{|l|r|r|}
\hline & Indirect Effect of Social Problems & 95\% Confidence Interval \\
\hline NEM & .083 & -.023 to .213 \\
\hline SUR & -.114 & -.298 to .014 \\
\hline AF & -.009 & -.115 to .069 \\
\hline \multicolumn{2}{|c|}{ NEM = Negative Emotionality; SUR = Surgency; AF = Affiliation }
\end{tabular}




\section{Discussion}

\section{Overview of Results}

We found that adolescents' internalizing symptoms and their social-externalizing problems at age 12 predicted unique variance in the subsequent development of MDD during adolescence. Internalizing symptoms significantly mediated the relationship between all predicted measures of temperament and the development of MDD. Specifically, higher levels of negative emotionality and affiliation during early adolescence predicted higher levels of internalizing symptoms, which in turn predicted the development of MDD. Lower levels of effortful control and surgency also predicted higher levels of internalizing symptoms, which in turn predicted the development of MDD. In addition, adolescent externalizing social problems mediated the relationship between effortful control and MDD, such that lower levels of effortful control predicted more social problems, which in turn predicted a diagnosis of MDD. Overall, significantly more adolescent girls developed depression than boys, while boys tended to have significantly higher levels of externalizing problems. These latter findings are consistent with the literature on sex differences in depression and externalizing problems [127]. We also found that individuals who developed depression had significantly higher symptom scores for the BAI, CESD, and CBCL social problems subscale at age 12, compared to those who did not develop depression. 


\section{Symptom Pathways and Major Depressive Disorder}

The main hypothesis that internalizing and externalizing problems predicted unique pathways to the development of depression was partially supported by the findings. Internalizing problems were found to represent a unique predictive factor pathway for MDD, which is consistent with the previous literature on adults and depression [41, 78, 79]. Surprisingly, externalizing problems, as a whole, did not represent a unique predictive pathway for MDD. This is inconsistent with Kendler, Gardner, and Prescott's [41, 78] research, which demonstrated support for distinct internalizing, externalizing, and interpersonal pathways to depression. The externalizing pathway in their analysis was comprised of reported conduct disorder and substance abuse, but they sampled adult populations, rather than adolescent populations. Also, Lewinsohn, Gotlib, and Seeley found evidence for a predictive relationship between externalizing symptoms, substance abuse, and MDD in older adolescent populations [2]. The current study's method for accessing externalizing symptoms and the age of assessment may help explain why an externalizing pathway was not found. Parent reports were used in the current analysis to quantify externalizing problems. This could contribute to the insignificant findings for an externalizing pathway, given that parents are unlikely to be around when children are participating in recreational substance use or in other illegal behaviors, such as theft or vandalism. In addition, externalizing symptoms were recorded around age 12, which may also account for the lack of a significant externalizing pathway, given that behaviors such as drinking and other substance use do not typically emerge until later in development [128]. 
While the study did not find support for an externalizing pathway to depression a significant pathway was found for externalizing social problems. The social problems subscale of the CBCL measures adolescents' tendencies to be rejected and disliked by peers, bullied, isolated, and withdrawn. This social-externalizing factor may represent the effects of aggressive and bully-like tendencies in certain adolescents. Aggressive and bully-like behaviors can create negative social environments for the perpetrator that in turn disrupt social relationships and increase vulnerability to MDD. The proposed relationship between aggression and social problems in our sample is consistent with the literature that has shown associations between aggression, social rejection, and depressive symptoms [46, 47, 58, 59]. Additionally, this social-externalizing pathway may reflect Kendler, Gardner and Prescott's interpersonal pathway to depression among adults, which is characterized by stressful life events, low social support, and marital problems, among other factors [41].

\section{Temperament, Symptom Pathways, and Major Depressive Disorder}

The temperamental hypotheses for internalizing disorders were supported by the current study, and align with previous literature on the relationship between temperament, internalizing symptoms, and MDD [92, 93, 110, 113, 115, 116]. High negative emotionality, high affiliation, low effortful control, and low surgency were all significantly associated with an internalizing pathway towards depression. High negative emotionality is reflective of high levels of sadness, frustration, and anger. A significant mediational relationship existed among negative emotionality, internalizing problems, and depression, such that high levels of negative emotionality predicted an 
increase in internalizing problems, which in turn increased the risk for developing depression. Furthermore, high levels of affiliation, which reflect individuals who place a strong emphasis on close relationships, predicted increased internalizing problems, which in turn predicted depression. This outcome lends evidence to support previous literature proposing that high affilitiative need renders individuals more sensitive to interpersonal stressors, which can lead to an increased expression of internalizing symptoms [113, 115]. Furthermore, low surgency represented a risk factor for the internalizing pathway to depression, as higher levels of shyness and fear predicted elevated internalizing problems, which predicted a diagnosis of depression. Low effortful control also represented a risk factor for the internalizing pathway of depression. Lower levels of effortful control, which are reflective of a diminished ability to self-regulate emotions and behaviors within specific social contexts, predicted increased internalizing symptoms, which subsequently predicted depression.

Our hypothesis also predicted that low effortful control and high negative emotionality would be associated with an externalizing pathway of depression. However, externalizing problems were not a significant overall predictor of MDD. Nevertheless, the social problems facet of the CBCL did predict MDD, and so temperamental mediation analysis was conducted on this subcomponent pathway. In this sense the original hypothesis was partially supported and refined by the current analyses. Although no specific hypotheses were made for this social component of externalizing problems, low effortful control was found to be significantly associated with elevated social problems and MDD. This finding is consistent with the notion that 
social problems may be a key facet of externalizing problems conferring risk for MDD during adolescent development.
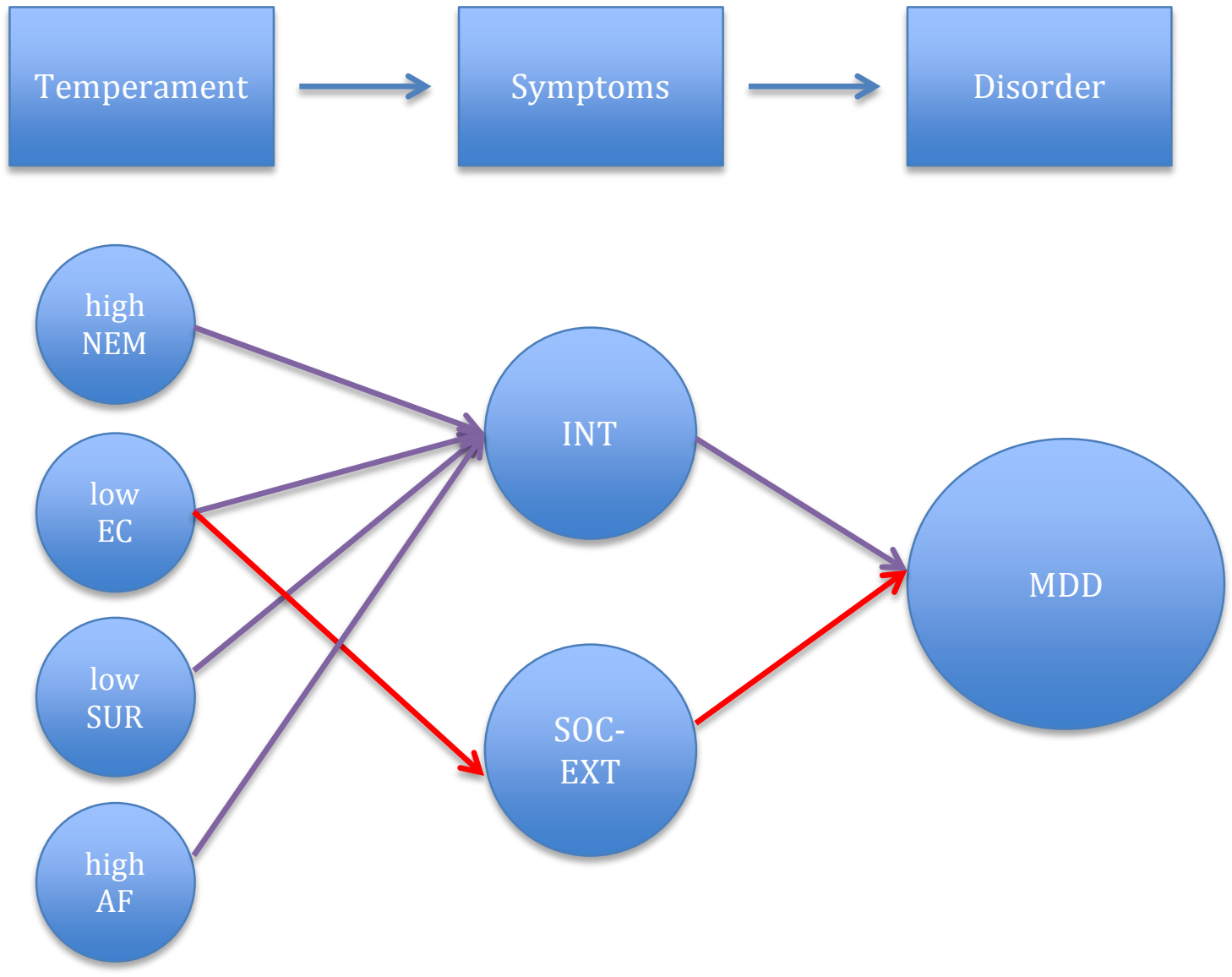

Figure 9 - Established Specific Pathways Towards MDD (Red arrows represent the social-externalizing pathway. Purple arrows represent the internalizing pathway) NEM = Negative Emotionality; EC = Effortful Control; SUR = Surgency; AF = Affiliation; INT = Internalizing Symptoms; SOC-EXT = Social-Externalizing Symptoms; MDD = Major Depressive Disorder

\section{Theoretical Implications}

The pattern of results align with a range of interpersonal models of depression [129], including the social risk hypothesis of depression, which states that social 
disruption and dysfunction are the final common pathway to developing depression [130]. These models are rooted in the fact that humans are inherently social creatures, which gives us a strong need to belong and maintain feelings of connectedness. Our social nature makes us highly sensitive to how we are perceived by others, which is heightened during adolescence [131-135]. Self-esteem, which is rooted in the social environment, is highly related to our interpersonal connections and sense of social belongingness. Unsurprisingly, individuals who are neglected, rejected, and perform poorly in socially valued areas of life tend to have lower self-esteem [136, 137], which in turn has been shown to predict depressive symptoms [138-140]. In fact, depression is highly related to individuals with hypersensitivity to social risk and exclusion [130]. These individuals tend to feel powerless in their environment, and as a consequence tend to withdraw and isolate themselves. They feel defeated and tend to make more unfavorable social comparisons. These individuals may also be more likely to engage in excessive reassurance seeking and negative feedback seeking, which represent additional depressive risk factors [129].

Our model of depression suggests a common pathway between internalizing and externalizing problems and depression, characterized by these negative social experiences. Adolescents who are aggressive and disruptive toward peers are more likely to be socially rejected and become isolated. The social-externalizing problems pathway encompasses these aspects of rejection, isolation, and withdrawal, which are related to lowered self-esteem. The internalizing pathway is characterized by individuals who are also withdrawn, shy, isolated, and have low self-esteem. The 
predictive ability of these social risk factors suggests that depression during adolescence may be distinctively related to social factors.

Furthermore, low effortful control, which reflects one's ability to regulate and control behavior and emotions, is a common risk factor that predicts both the internalizing and social-externalizing pathways to depression. This suggests that high effortful control is likely to be a protective factor for those who may be at risk for depression, which is consistent with the literature (e.g. [12]). The literature suggests that, within the context of social experiences, adolescents who have difficult, antagonistic, or isolated relationships with peers are more likely to experience negative social and emotional consequences (e.g. [43]). Adolescents who cannot control aggressive emotional and physical outbursts are likely to find themselves rejected by and isolated from their peers (e.g. [46]). Moreover, adolescents who may already be shy, withdrawn, or have low self-esteem and, in addition, have a difficult time selfregulating their emotions, may tend to ruminate and compare themselves negatively to peers (e.g. [12, 102, 141]). Rumination can lead to excessive reassurance seeking, which can also negatively impact social relationships by eliciting rejection [129]. The inability to successfully navigate these social experiences provides a risk factor for depression. The ability to self-regulate negative emotions and behaviors is particularly important when experiencing adverse social experiences and helps explain why this temperamental dimension is important for risk-reduction. The mediational relationship among temperament, internalizing symptoms, and depression is consistent with this theoretical and empirical temperament literature. Thus, this study provides further 
support for temperament as a predictive risk factor for depressive and anxious symptoms, and the subsequent development of depression [129].

\section{Additional Limitations and Strengths}

Apart from those outlined above, there are additional limitations and strengths that should be borne in mind, considering the implications of these findings. The reported pathways to depression and their temperamental associations should be interpreted within the context of our study's methodological limitations. First, parent CBCL reports may represent a biased measure in our analyses. Parent reports on the CBCL are typically considered more reliable than child self-reports, however, they may be less valid given that parents are unlikely to be around during instances of substance use and vandalism, and other negative expressions of behavior. Additionally, there may be sampling biases due to the lower participation rate at the school, family and individual level. However, among those selected for the risk-enriched sample, there were not significant differences between participants and those who declined to continue with respect to negative emotionality, effortful control, sex, ethnicity, and socioeconomic status (see Methods, 'Participants'). Attrition also represents a potential source of bias, although we partially accounted for this through the imputation of missing data. Next, the attrition from T1 to T4 represents a potential source of biases. To partially account for this effect we used the recommended statistical approach to account for and impute missing data [125]. The generalizability of the study may also be limited by the longitudinal design because there may be historical differences between those in the study and future or past adolescents. 
Another potential limiting factor was the use of MDD as a dichotomous outcome variable, which does not represent the full spectrum of depression that exists, but the dichotomous distinction is typical of how mood and other disorders are clinically diagnosed. Individuals who were just below threshold levels of MDD were not included in the depressive sample. However, we did find a significant association between temperament and the continuous variable of internalizing symptoms, including symptoms of depression, which are a risk factor for developing depression later in life. In addition, the study did not account for other diagnostic outcomes, which may be especially important given recent findings suggesting that risk factors may be transdiagnostic (e.g. [2, 98]).

We also did not account socioeconomic status (SES) in our analysis. SES can influence the prevalence and severity of mental disorders and thus can be a relevant factor to examine (e.g. [142-144]), but there have been mixed findings within the literature concerning the relationship between SES and depression (e.g. [16, 145]). Future research should examine the effects of SES on symptom pathways and temperament in relation to prevalence and severity of MDD. Finally, our sample size was somewhat small, which may have limited the ability of our logistic regression analysis to detect significant differences and relationships.

However, the study also had numerous strengths and advantages. The longitudinal design allows for stronger conclusions about the predictive value of internalizing and externalizing risk factors in the development of MDD. The strength of the symptom scales used allows for broader interpretations of our results and for direct comparisons among the literature. Using a measure of temperament at one point in time 
can be a limitation, especially if it temporally overlaps with measurements of symptoms. However, we averaged temperament scores between $\mathrm{T} 0$ and $\mathrm{T} 1$ creating a more stable trait-like measure by protecting against day-to-day variation in temperament scores. This approach also provides the temporal relationship necessary to conduct stronger mediation analysis.

\section{Future Research and Interventions}

Future research should use larger longitudinal samples to examine the presence of both internalizing and externalizing pathways to test if the size of our sample limited our ability to detect the presence of other externalizing risk factors for depression. In addition future research should explore specific social problems related to depression to illuminate the corresponding type of negative social outcome. Future research should also use methodology that does not rely solely on self and parent reported data. Methods such as interviews with the child, parent, or teachers, as well as teacher reports should be taken advantage of to better understand the details related to social problems and depression. Parent-child attachment would be another risk factor worth exploring, as familial attachment may predict social well-being.

While the current study focused on MDD, other studies should examine additional clinical and non-clinical outcomes such as anxiety disorders, substance abuse, conduct disorder, and scholastic achievement, given the high co-occurrence of depression and other disorders. The current study consisted of a largely ethnically homogeneous sample [118], and so future research should also test the existence of socially-based risk factors for MDD cross culturally, and amongst different ethnic 
communities. In addition, future research should explore how social factors, such as isolation and peer rejection, predict the occurrence and severity of depressive episodes. Examining the effect of social skills training for individuals suffering from depression who also have inadequate social environments (i.e. low numbers of and low quality of friendships) would be particularly important for intervention therapies. Another direction for research would explore how interpersonal problems interact with underlying neurobiological mechanisms and different cognitive styles, which may amplify risk for a depressive episode.

An additional factor worth exploring would be the stage of pubertal development, which may be more relevant to adolescent development than chronological age. Puberty is considered the most important developmental event in early adolescence, and it is during this time that significant sex differences in depression begin to emerge. New social relationship dynamics and hormonal increases have been associated with the experience of new emotions and affective states [146, 147]. The timing of these pubertal changes has been linked to increased internalizing symptoms, particularly in girls [148-151]. For girls, early maturation may lead to social adjustment problems [148, 152]. Given the conclusion of the current analysis on the importance of social relationships and the development of depression, the effect on pubertal timing, interpersonal problems, and depression should be examined.

The implications of our findings suggest that intervention and prevention therapies for MDD, and potentially other related disorders, should target young adolescents who are socially isolated, withdrawn, and excluded. These social characteristics represent a common pathway for internalizing and externalizing risk 
factors in the development of MDD. Temperament also emerged as a significant factor for targeting early-adolescents who may be at risk for depression. Surgency, affiliation, effortful control, and negative emotionality all significantly predicted the expression of internalizing symptoms, which subsequently predicted an outcome of depression. Using temperament to target intervention is advantageous because it can be assessed quickly and with minimal resources.

Interventions should also focus on self-regulation of emotions and behavior because effortful control was shown to be a protective factor for both internalizing and social-externalizing pathways to depression. Intervention and prevention efforts may also want to focus on the range of preceding factors for social problems since both extreme aggression and extreme shyness can elicit peer rejection. Aggressive children may need different types of social skill intervention compared to children who are shy and withdrawn. The focus of these interventions, however, should be on social processes and self-regulation.

\section{Conclusion}

We tested the hypothesis that internalizing symptoms, defined by the BAI and CESD, and externalizing symptoms, defined by the CBCL, would predict unique pathways for the development of MDD. We also examined whether these symptoms mediated the relationship between temperament and MDD for these two pathways. We found that internalizing symptoms and social-externalizing symptoms at age 12 predicted the development of MDD through adolescence. This suggests that social factors represent a common pathway to depression, which may support the social risk hypothesis of depression. Speculatively, adolescents who cannot successfully navigate 
the social world may be excluded by peers, withdraw from social settings, and have lower levels of self-esteem, although further research is required to evaluate this explanation. Additionally, we found support for the existing body of evidence that has demonstrated associations between different temperamental traits and depressive symptoms and disorders. We successfully demonstrated an ability to identify children at risk for depression, as early as 12-years-old, using temperament scores from the EATQR. Effortful control emerged as a common risk factor between the internalizing and social-externalizing pathways to depression, which suggests that the ability to successfully self-regulate emotions and behavior represents a protective factor for adolescents with lower self-esteem and who may be isolated, shy, and rejected by their peers. 


\section{Bibliography}

1. Rueter, M.a., et al., First onset of depressive or anxiety disorders predicted by the longitudinal course of internalizing symptoms and parent-adolescent disagreements. Archives of General Psychiatry, 1999. 56(8): p. 726-732.

2. Lewinsohn, P.M., I.H. Gotlib, and J.R. Seeley, Adolescent psychopathology: IV. Specificity of psychosocial risk factors for depression and substance abuse in older adolescents. Journal of the American Academy of Child and Adolescent Psychiatry, 1995. 34(9): p. 1221-1229.

3. Ustun, T.B., et al., Global burden of depressive disorders in the year 2000. The British Journal of Psychiatry, 2004. 184(5): p. 386-392.

4. Kovacs, M. and D. Goldston, Cognitive and Social Cognitive Development of Depressed Children and Adolescents. Journal of the American Academy of Child \& Adolescent Psychiatry, 1991. 30(3): p. 388-392.

5. Lilienfeld, S.O., Comorbidity between and within childhood externalizing and internalizing disorders: Reflections and direction. Journal of Abnormal Child Psychology, 2003. 31(3): p. 285-291.

6. Birmaher, B., et al., Childhood and Adolescent Depression: A Review of the Past 10 Years. Part I. Journal of the American Academy of Child \& Adolescent Psychiatry, 1996. 35(11): p. 1427-1439.

7. Harrington, R. and P. Vostanis, Longitudinal perspectives and affective disorder in children and adolescent. The Depressed Child and Adolescent ed. I.M. Goodyer. 1995, Cambridge, UK: Cambridge University Press.

8. Lewinsohn, P.M., et al., Psychosocial functioning of young adults who have experienced and recovered from major depressive disorder during adolescence. Journal of Abnormal Psychology, 2003. 112: p. 353-363.

9. Costello, J.E., A. Erkanli, and A. Angold, Is there an epidemic of child or adolescent depression? Journal of Child Psychology and Psychiatry and Allied Disciplines, 2006. 47(12): p. 1263-1271.

10. Clarke, G.N., et al., School-Based Primary Prevention of Depressive Symptomatology in Adolescents: Findings from Two Studies. Journal of Adolescent Research, 1993. 8(2): p. 183-204.

11. Lewinsohn, P.M., et al., Adolescent psychopathology: I. Prevalence and incidence of depression and other DSM-III--R disorders in high school students. Journal of Abnormal Psychology, 1993. 102(1): p. 133-144.

12. Verstraeten, K., et al., Temperament and risk for depressive symptoms in adolescence: Mediation by rumination and moderation by effortful control. Journal of Abnormal Child Psychology, 2009. 37(3): p. 349-361.

13. Whitaker, A., et al., Uncommon Troubles in Young People. Archives of General Psychiatry, 1990. 47(5): p. 487-496.

14. Hankin, B.L., et al., Development of depression from preadolescence to young adulthood: Emerging gender differences in a 10-year longitudinal study. Journal of Abnormal Psychology, 1998. 107(1): p. 128-140.

15. Nolen-Hoeksema, S. and J.S. Girgus, The emergence of gender differences in depression during adolescence. Psychological Bulletin, 1994. 115(3): p. 424-443.

16. Twenge, J.M. and S. Nolen-Hoeksema, Age, gender, race, socioeconomic status, and birth cohort difference on the children's depression inventory: A meta-analysis. Journal of Abnormal Psychology, 2002. 111(4): p. 578-588. 
17. Yap, M.B.H., N.B. Allen, and L. Sheeber, Using an Emotion Regulation Framework to Understand the Role of Temperament and Family Processes in Risk for Adolescent Depressive Disorders. Clinical Child and Family Psychology Review, 2007. 10(2): p. 180-196.

18. Allen, N.B. and L.B. Sheeber, The importance of affective development for the emergence of depressive disorders during adolescence. Adolescent Emotional Development and the Emergence of Depressive Disorders, ed. N.B. Allen and L.B. Sheeber. 2012, New York, NY: Cambridge University Press 1-10.

19. Nelson, E.E., et al., The social re-orientation of adolescence: a neuroscience perspective on the process and its relation to psychopathology. Psychological Medicine, 2005. 35(2): p. 163-174.

20. Spear, L.P., The adolescent brain and age-related behavioral manifestations. Neuroscience \& Biobehavioral Reviews, 2000. 24(4): p. 417-463.

21. Steinberg, L., Cognitive and affective development in adolescence. Trends in Cognitive Sciences, 2005. 9(2): p. 69-74.

22. Book, A.S., K.B. Starzyk, and V.L. Quinsey, The relationship between testosterone and aggression: a meta-analysis. Aggression and Violent Behavior, 2001. 6(6): p. 579-599.

23. Rowe, R., et al., Testosterone, antisocial behavior, and social dominance in boys: pubertal development and biosocial interaction. Biological Psychiatry, 2004. 55(5): p. 546-552.

24. Graber, J.A., Pubertal and neuroendocrine development and risk for depression. Adolescent Emotional Development and the Emergence of Depressive Disorders, ed. N.B. Allen and L.B. Sheeber. 2012, New York, NY: Cambridge University Press

25. Brown, B.B., Adolescents' Relationships with Peers. 2nd ed. Handbook of Adolescent Psychology, ed. R.M. Lerner and L.D. Steinberg. 2004, Hoboken, NJ: John Wiley \& Sons. 363-394.

26. Brown, B.B. and C. Klute, Friendships, Cliques, and Crowds. Blackwell Handbook of Adolescence. 2003, Malden, MA: Blackwell. 330-348.

27. Steinberg, L., et al., The study of developmental psychopathology in adolescence: Integrating affective neuroscience with the study of context. Developmental Psychopathology, Volume 2, Developmental Neuroscience, ed. D. Cicchetti and D. Cohen. 2006, Hoboken, NJ: John Wiley \& Sons. .

28. Steinberg, L. and A.S. Morris, Adolescent Development. Annual Review of Psychology, 2001. 52(1): p. 83-110.

29. Larson, R.E. and M.H. Richards, Divergent Realities: The Emotional Lives of Mothers, Fathers, and Adolescents. 1994, New York, NY: Basic Books.

30. Kesek, A., P.D. Zelazo, and M.D. Lewis, The development of executive cognitive function and emotion regulation in adolescence. Adolescent Emotional Development and the Emergence of Depressive Disorders, ed. N.B. Allen and L.B. Sheeber. 2012, New York, NY: Cambridge University Press 135-155.

31. Gutman, L.M. and J.S. Eccles, Stage-environment fit during adolescence: Trajectories of family relations and adolescent outcomes. Developmental Psychology, 2007. 43(2): p. 522-537.

32. Steinberg, L., We Know Some Things: Parent-Adolescent Relationships in Retrospect and Prospect. Journal of Research on Adolescence, 2001. 11(1): p. 1-19. 
33. Olino, T.M., et al., Latent trajectory classes of depressive and anxiety disorders from adolescence to adulthood: descriptions of classes and associations with risk factors. Comprehensive Psychiatry, 2010. 51(3): p. 224-235.

34. Hale, W.W., et al., One factor or two parallel processes? Comorbidity and development of adolescent anxiety and depressive disorder symptoms. Journal of Child Psychology and Psychiatry, 2009. 50(10): p. 1218-1226.

35. Leadbeater, B., K. Thompson, and V. Gruppuso, Co-occurring Trajectories of Symptoms of Anxiety, Depression, and Oppositional Defiance From Adolescence to Young Adulthood. Journal of Clinical Child \& Adolescent Psychology, 2012. 41(6): p. 719-730.

36. Clark, L.A., Depressive and anxiety disorders: Descriptive psychopathology and differential diagnosi. Anxiety and depression: Distinctive and overlapping features. 1989, New York, NY: Academic Press.

37. Kessler, R.C., et al., The Epidemiology of Major Depressive Disorder. The Journal of the American Medical Association 2003. 289(23): p. 3095.

38. Mineka, S., D. Watson, and L.A. Clark, Comorbidity of Anxiety and Unipolar Mood Disorders. Annual Review of Psychology, 1998. 49(1): p. 377-412.

39. Ollendick, T., et al., Comorbidity as a predictor and moderator of treatment outcome in youth with anxiety, affective, attention deficit/hyperactivity disorder, and oppositional/conduct disorders. Clinical Psychology Review, 2008. 28(8): p. 1447-1471.

40. Starr, L.R. and J. Davila, Differentiating Interpersonal Correlates of Depressive Symptoms and Social Anxiety in Adolescence: Implications for Models of Comorbidity. Journal of Clinical Child \& Adolescent Psychology, 2008. 37(2): p. 337-349.

41. Kendler, K.S., C.O. Gardner, and C.A. Prescott, Toward a comprehensive developmental model for major depression in men. The American Journal of Psychiatry, 2006. 163(1): p. 115-124.

42. Roza, S.J., et al., Stable Prediction of Mood and Anxiety Disorders Based on Behavioral and Emotional Problems in Childhood: A 14-Year Follow-Up During Childhood, Adolescence, and Young Adulthood. American Journal of Psychiatry, 2003. 160(12): p. 2116-2121.

43. Newcomb, A.F. and W.M. Bukowski, A Longitudinal Study of the Utility of Social Preference and Social Impact Sociometric Classification Schemes. Child Development, 1984. 55(4): p. 1434.

44. Bierman, K.L., Peer Rejection. 2004, New York, NY: Guilford Press.

45. Parker, J.G. and S.R. Asher, Peer relations and later personal adjustment: Are low-accepted children at risk? Psychological Bulletin, 1987. 102(3): p. 357-389.

46. Rubin, K.H., W. Bukwski, and J.G. Parker, Peer interactions, relationships, and groups. 6th ed. Handbook of Child Psychology: Vol 3. Social, Emotional, and Personality Development ed. W. Damon. 2006, New York, NY: Wiley

47. Furman, W., C. McDunn, and B.J. Young, The role of peer and romantic relationships in adolescent affective development. Adolescent Emotional Development and the Emergence of Depressive Disorders, ed. N.B. Allen and L.B. Sheeber. 2012, New York, NY: Cambridge University Press 299317. 
48. Saluja, G., et al., Prevalence of and risk factors for depressive symptoms among young adolescents. Archives of Pediatrics \& Adolescent Medicine, 2004. 158(8): p. 760-765.

49. Pellegrini, A.D. and J.D. Long, A longitudinal study of bullying, dominance, and victimization during the transition from primary school through secondary school. British Journal of Developmental Psychology, 2002. 20(2): p. 259-280.

50. Tackett, J.L., et al., Viewing relational aggression through multiple lenses: Temperament, personality, and personality pathology. Development and Psychopathology, 2014. 26(03): p. 863-877.

51. Card, N.A., et al., Direct and indirect aggression during childhood and adolescence: A meta-analytic review of gender differences, intercorrelations, and relations to maladjustment. Child Development, 2008. 79: p. 1185-1229.

52. Preddy, T.M. and P.J. Fite, Differential Associations Between Relational and Overt Aggression and Children's Psychosocial Adjustment. Journal of Psychopathology and Behavioral Assessment, 2012. 34(2): p. 182-190.

53. Grotpeter, J.K. and N.R. Crick, Relational Aggression, Overt Aggression, and Friendship. Child Development, 1996. 67(5): p. 2328-2338.

54. Murray-Close, D., J.M. Ostrov, and N.R. Crick, A short-term longitudinal study of growth of relational aggression during middle childhood:

Associations with gender, friendship intimacy, and internalizing problems. Development and Psychopathology, 2007. 19(01): p. 187-203.

55. $\quad$ Prinstein, M.J., J. Boergers, and E.M. Vernberg, Overt and Relational Aggression in Adolescents: Social-Psychological Adjustment of Aggressors and Victims. Journal of Clinical Child \& Adolescent Psychology, 2001. 30(4): p. 479-491.

56. Tackett, J.L. and J.M. Ostrov, Measuring Relational Aggression in Middle Childhood in a Multi-Informant Multi-Method Study. Journal of Psychopathology and Behavioral Assessment, 2010. 32(4): p. 490-500.

57. Werner, N.E. and N.R. Crick, Relational aggression and socialpsychological adjustment in a college sample. Journal of Abnormal Psychology, 1999. 108(4): p. 615-623.

58. Deater-Deckard, K., Annotation: Recent Research Examining the Role of Peer Relationships in the Development of Psychopathology. Journal of Child Psychology and Psychiatry, 2001. 42(5): p. 565-579.

59. Ladd, G.W., Peer Relationships and Social Competence During Early and Middle Childhood. Annual Review of Psychology, 1999. 50(1): p. 333-359.

60. Hodges, E.V.E. and D.G. Perry, Personal and interpersonal antecedents and consequences of victimization by peers. Journal of Personality and Social Psychology, 1999. 76(4): p. 677-685.

61. La Greca, A.M. and H.M. Harrison, Adolescent Peer Relations, Friendships, and Romantic Relationships: Do They Predict Social Anxiety and Depression? Journal of Clinical Child \& Adolescent Psychology, 2005. 34(1): p. 49-61.

62. Angold, A. and E.J. Costello, Depressive comorbidity in children and adolescents: empirical, theoretical, and methodological issues. American Journal of Psychiatry, 1993. 150(12): p. 1779-1791.

63. Bird, H.R., M.S. Gould, and B.M. Staghezza, Patterns of Diagnostic Comorbidity in a Community Sample of Children Aged 9 through 16 Years. 
Journal of the American Academy of Child \& Adolescent Psychiatry, 1993. 32(2): p. 361-368.

64. Drabick, D.A.G., et al., Risk Factors for Conduct Problems and Depressive Symptoms in a Cohort of Ukrainian Children. Journal of Clinical Child \& Adolescent Psychology, 2006. 35(2): p. 244-252.

65. Fleming, J.E., M.H. Boyle, and D.R. Offord, The Outcome of Adolescent Depression in the Ontario Child Health Study Follow-up. Journal of the American Academy of Child \& Adolescent Psychiatry, 1993. 32(1): p. 2833.

66. Hewitt, J.K., et al., Genetics and Developmental Psychopathology: 1. Phenotypic Assessment in the Virginia Twin Study of Adolescent Behavioral Development. Journal of Abnormal Child Psychology, 1997. 38(8): p. 943963.

67. Pliszka, S.R., et al., Affective Disorder in Juvenile Offenders: A Preliminary Study. American Journal of Psychiatry, 2000. 157(1): p. 130-132.

68. Zoccolillo, M., Co-occurrence of Conduct Disorder and Its Adult Outcomes with Depressive and Anxiety Disorders: A Review. Journal of the American Academy of Child \& Adolescent Psychiatry, 1992. 31(3): p. 547-556.

69. Kashani, J.H., et al., Depression among incarcerated delinquents. Psychiatry Research, 1980. 3(2): p. 185-191.

70. $\quad$ Costello, E.J., et al., Development of Psychiatric Comorbidity With Substance Abuse in Adolescents: Effects of Timing and Sex. Journal of Clinical Child Psychology, 1999. 28(3): p. 298-311.

71. Riggs, P.D., et al., Depression in Substance-Dependent Delinquents. Journal of the American Academy of Child \& Adolescent Psychiatry, 1995. 34(6): p. 764-771.

72. Cole, D.A. and S. Carpentieri, Social status and the comorbidity of child depression and conduct disorder. Journal of Consulting and Clinical Psychology, 1990. 58(6): p. 748-757.

73. Rapp, L.A. and J.S. Wodarski, The comorbidity of conduct disorder and depression in adolescents: A comprehensive interpersonal treatment technolog. Family Therapy, 1997. 24(2): p. 81-100.

74. Althoff, R.R., et al., Adult Outcomes of Childhood Dysregulation: A 14-year Follow-up Study. Journal of the American Academy of Child \& Adolescent Psychiatry, 2010. 49(11): p. 1105-1116.e1.

75. Rowe, R., et al., Developmental pathways in oppositional defiant disorder and conduct disorder. Journal of Abnormal Psychology, 2010. 119(4): p. 726-738.

76. Stringaris, A. and R. Goodman, Longitudinal Outcome of Youth Oppositionality: Irritable, Headstrong, and Hurtful Behaviors Have Distinctive Predictions. Journal of the American Academy of Child \& Adolescent Psychiatry, 2009. 48(4): p. 404-412.

77. Loth, A.K., et al., Do Childhood Externalizing Disorders Predict Adult Depression? A Meta-Analysis. Journal of Abnormal Child Psychology, 2014. 42(7): p. 1103-1113.

78. Kendler, K.S., C.O. Gardner, and C.A. Prescott, Toward a comprehensive developmental model for major depression in women. The American Journal of Psychiatry, 2002. 159(7): p. 1133-1145. 
79. Kendler, K.S. and C.O. Gardner, Sex Differences in the Pathways to Major Depression: A Study of Opposite-Sex Twin Pairs. American Journal of Psychiatry, 2014. 171(4): p. 426-435.

80. Rothbart, M.K. and J.E. Bates, Temperament 5th ed. Handbook of child psychology: Vol. 3. Social, emotional, and personality develop- ment, ed. W. Damon. 1998, New York, NY: Wiley

81. Shiner, R.L., How shall we speak of children's personalities in middle childhood? A preliminary taxonomy. Psychological Bulletin, 1998. 124(3): p. 308-332.

82. Whittle, S., et al., The neurobiological basis of temperament: towards a better understanding of psychopathology. Neuroscience \& Biobehavioral Reviews, 2006. 30(4): p. 511-525.

83. Lengua, L.J., Growth in temperament and parenting as predictors of adjustment during children's transition to adolescence. Developmental Psychology, 2006. 42(5): p. 819-832.

84. Putnam, S.K., L.K. Ellis, and M.K. Rothbart, The structure of temperament from infancy through adolescence. Advances/Proceedings in Research on Temperament ed. A. Eliasz and A. Angleitner. 2001, Miami, FL: Pabst Scientist Publisher

85. Thomas, A. and S. Chess, Temperament and development. 1977, Oxford, England: Brunner/Mazel.

86. Compas, B.E., J. Connor-Smith, and S.S. Jaser, Temperament, Stress Reactivity, and Coping : Implications for Depression in Childhood and Adolescence. Journal of Clinical Child and Adolescent Psychology, 2004. 33(1): p. 21-31.

87. Lonigan, C.J., et al., Positive and negative affectivity in children: Confirmatory factor analysis of a two-factor model and its relation to symptoms of anxiety and depression. Journal of Consulting and Clinical Psychology, 1999. 67(3): p. 374-386.

88. Rothbart, M.K., S.A. Ahadi, and D.E. Evans, Temperament and personality: Origins and outcomes. Journal of Personality and Social Psychology, 2000. 78(1): p. 122-135.

89. Muris, P. and T.H. Ollendick, The role of temperament in the etiology of child psychopathology. Clinical Child and Family Psychology Review, 2005. 8(4): p. 271-289.

90. Rothbart, M., Temperament and development. Temperament in childhood, ed. G. Kohnstamm, J. Bates, and M. Rothbart. 1989, New York: Wiley.

91. Clark, L.A. and D. Watson, Tripartite model of anxiety and depression: Psychometric evidence and taxonomic implications. Journal of Abnormal Psychology, 1991. 100(3): p. 316-336.

92. Cummings, C.M., N.E. Caporino, and P.C. Kendall, Comorbidity of anxiety and depression in children and adolescents: 20 years after. Psychological Bulletin, 2014. 140(3): p. 816-845.

93. De Bolle, M., et al., Affective Determinants of Anxiety and Depression Development in Children and Adolescents: An Individual Growth Curve Analysis. Child Psychiatry and Human Development, 2011. 42(6): p. 694711.

94. Clark, L.A., Temperament as a Unifying Basis for Personality and Psychopathology. Journal of Abnormal Psychology, 2005. 114(4): p. 505521. 
95. Khan, A.A., et al., Personality and comorbidity of common psychiatric disorders. The British Journal of Psychiatry, 2005. 186(3): p. 190-196.

96. Klein, D.N., et al., Temperament and risk for mood disorders in adolescents. Adolescent Emotional Development and the Emergence of Depressive Disorders, ed. N.B. Allen and L.B. Sheeber. 2012, New York, NY: Cambridge University Press 238-261.

97. Kochanska, G., K.T. Murray, and E.T. Harlan, Effortful control in early childhood: Continuity and change, antecedents, and implications for social development. Developmental Psychology, 2000. 36(2): p. 220-232.

98. De Pauw, S.S.W. and I. Mervielde, Temperament, personality and developmental psychopathology: A review based on the conceptual dimensions underlying childhood traits. Child Psychiatry and Human Development, 2010. 41(3): p. 313-329.

99. Krueger, R.F., The Structure of Common Mental Disorders. The Archive of General Psychiatry 1999. 56(10): p. 921-926.

100. Livesley, W.J., K.L. Jang, and P.A. Vernon, Phenotypic and Genetic Structure of Traits Delineating Personality Disorder. Archives of General Psychiatry, 1998. 55(10): p. 941-948.

101. Swendsen, J.D., et al., Are Personality Traits Familial Risk Factors for Substance Use Disorders? Results of a Controlled Family Study. American Journal of Psychiatry, 2002. 159(10): p. 1760-1766.

102. Eisenberg, N., et al., Longitudinal relations of children's effortful control, impulsivity, and negative emotionality to their externalizing, internalizing, and co-occurring behavior problems. Developmental psychology, 2009. 45(4): p. 988-1008.

103. Achenbach, T.M., Manual for the child behavior checklist/4-18 and 1991 profile. . 1991, University of Vermont, Department of Psychiatry Burlington.

104. Lennox, C. and M. Dolan, Temperament and character and psychopathy in male conduct disordered offenders. Psychiatry Research, 2014. 215(3): p. 706-710.

105. Lewinsohn, P.M., et al., Adolescent psychopathology: II. Psychosocial risk factors for depression. Journal of Abnormal Psychology, 1994. 103(2): p. 302-315.

106. Davila, J., et al., Poor interpersonal problem solving as a mechanism of stress generation in depression among adolescent women. Journal of Abnormal Psychology, 1995. 104(4): p. 592-600.

107. Caspi, A. and R.L. Shiner, Personality development. 6th ed. Handbook of Child Psychology, Sixth Edition: Social, Emotional, and Personality Development ed. W. Damon. Vol. 3. 2006, New York, NY: Wiley

108. Ellis, L.K. and M.K. Rothbart, Revision of the early adolescent temperament questionnaire. Society for Research in Child Development, 2001. 81: p. 1-5.

109. Ellis, L.K. and M.K. Rothbart, Revision of the Early Adolescent Temperament Questionnaire, in Biennial Meeting of the Society for Research in Child Development 2001: Minneapolis, Minnesota

110. Leve, L.D., H.K. Kim, and K.C. Pears, Childhood Temperament and Family Environment as Predictors of Internalizing and Externalizing Trajectories From Ages 5 to 17. Journal of Abnormal Child Psychology, 2005. 33(5): p. 505-520.

111. Derryberry, D. and M.A. Reed, Temperament and the self-organization of personality. Development and Psychopathology, 1994. 6(04): p. 653-676. 
112. Rothbart, M.K. and S.P. Putnam, Temperament and socialization.

Personality in the Life Course. 2002, Cambridge: Cambridge University Press 19-45.

113. Cyranowski, J.M., et al., Adolescent Onset of the Gender Difference in Lifetime Rates of Major Depression. Archives of General Psychiatry, 2000. 57(1): p. 21-57.

114. Panksepp, J., Affective neuroscience: The foundations of human and animal emotions. 1998, New York: Oxford University Press

115. Hoffmann, J.P. and S.S. Su, Stressful Life Events and Adolescent Substance Use and Depression: Conditional and Gender Differentiated Effects. Substance Use \& Misuse, 1998. 33(11): p. 2219-2262.

116. Klein, D.N., et al., Depression and personality. Handbook of Depression and its Treatment ed. I.H.G.C.L. Hammen. 2002, New York: Guilford Press.

117. Capaldi, D.M. and M.K. Rothbart, Development and validation of an early adolescent temperament measures. The Journal of Early Adolescence, 1992. 12(2): p. 153-173.

118. Yap, M.B.H., et al., Early adolescents' temperament, emotion regulation during mother-child interactions, and depressive symptomatology.

Development and Psychopathology, 2011. 23(1): p. 267-282.

119. Radloff, L.S., The CES-D Scale. Applied Psychological Measurement 1977. 1(3): p. 385-401.

120. Garrison, C.Z., et al., The CES-D as a screen for depression and other psychiatric disorders in adolescents Journal of the American Academy of Child \& Adolescent Psychiatry, 1991. 30(4): p. 636-641.

121. Roberts, R.E., P.M. Lewinsohn, and J.R. Seeley, Screening for adolescent depression: A comparison of depression scales. Journal of the American Academy of Child \& Adolescent Psychiatry, 1991. 30(1): p. 58-66.

122. Beck, A.T., et al., An inventory for measuring clinical anxiety: Psychometric properties. Journal of Consulting and Clinical Psychology, 1988. 56(6): p. 893-897.

123. Fydrich, T., D. Dowdall, and D.L. Chambless, Reliability and validity of the Beck Anxiety Inventory Journal of Anxiety Disorders 1992. 6(1): p. 55-61.

124. Kaufman, J., et al., Schedule for Affective Disorders and Schizophrenia for School-Age Children-Present and Lifetime version (K-SADS-PL): Initial reliability and validity data. Journal of the American Academy of Child and Adolescent Psychiatry, 1997. 36: p. 980-988.

125. Rubin, L.H., et al., Methods for Handling Missing Data in the Behavioral Neurosciences: Don't Throw the Baby Rat out with the Bath Water. Journal of Undergraduate Neuroscience Education 2007. 5(2): p. A71-A77.

126. Preacher, K.J. and A.F. Hayes, SPSS and SAS procedures for estimating indirect effects in simple mediation models. Behavior Research Methods, Instruments \& Computers, 2004. 36(4): p. 717-731.

127. Nolen-Hoeksema, S., Gender differences in depression. Handbook of Depression 2002, New York, NY: Guilford Press. 492-509.

128. Chen, P. and K. Jacobson, Developmental trajectories of substance use from early adolescence to young adulthood: Gender and racial/ethnic differences. Journal of Adolescent Health, 2012. 50(2): p. 154-163.

129. Joiner Jr., T.E. and K.A. Timmons, Handbook of depression. 2nd ed. 2008, New York, NY: Guilford Press. 
130. Allen, N.B. and P.B.T. Badcock, The social risk hypothesis of depressed mood: evolutionary, psychosocial, and neurobiological perspectives. Psychological bulletin, 2003. 129(6): p. 887-913.

131. Baumeister, R.F. and M.R. Leary, The need to belong: Desire for interpersonal attachments as a fundamental human motivation. Psychological Bulletin, 1995. 117(3): p. 497-529.

132. Bowlby, J., Attachment and loss. Vol. 1. 1969, New York: Basic Books

133. Gardner, W.L., C.L. Pickett, and M.B. Brewer, Social Exclusion and Selective Memory: How the Need to belong Influences Memory for Social Events. Personality and Social Psychology Bulletin, 2000. 26(4): p. 486-496.

134. Tooby, J. and L. Cosmides, Friendship and the banker's paradox: Other pathways to the evolution of adaptations for altruism. Proceedings of the British Academy, 1996. 88: p. 119-143.

135. Williams, K.D. and K.L. Sommer, Social Ostracism by Coworkers: Does Rejection Lead to Loafing or Compensation? Personality and Social Psychology Bulletin, 1997. 23(7): p. 693-706.

136. Leary, M.R., Responses to social exclusion: Social anxiety, jealously, loneliness, depression, and low self-esteem. . Journal of Social and Clinical Psychology 1990. 9: p. 221-229.

137. Maccoby, E.E. and J.A. Martin, Socialization in the context of the family: Parent-child interaction. . Handbook of Child Psychology Vol. 4. 1983, New York: Wiley.

138. Roberts, J.E., I.H. Gotlib, and J.D. Kassel, Adult attachment security and symptoms of depression: The mediating roles of dysfunctional attitudes and low self-esteem. Journal of Personality and Social Psychology, 1996. 70(2): p. 310-320.

139. Roberts, J.E. and S.M. Monroe, Vulnerable self-esteem and social processes in depression: Toward an interpersonal model of self-esteem regulation. Advances in interpersonal approaches: The interactional nature of depression. 1999, Washington, D.C.: American Psychological Association 149-187.

140. Tarlow, E.M. and D.A.F. Haaga, Negative Self-Concept: Specificity to Depressive Symptoms and Relation to Positive and Negative Affectivity. Journal of Research in Personality, 1996. 30(1): p. 120-127.

141. Kuster, F., U. Orth, and L.L. Meier, Rumination Mediates the Prospective Effect of Low Self-Esteem on Depression: A Five-Wave Longitudinal Study Personality and Social Psychology Bulletin, 2012. 38(6): p. 747-759.

142. Bruce, M.L., D.T. Takeuchi, and P.J. Leaf, Study, Poverty and psychiatric status. Longitudinal evidence from the New Haven Epidemiologic Catchment Area. Archive of General Psychiatry, 1991. 48: p. 470-474.

143. Gilman, S.E., et al., Socioeconomic status in childhood and the lifetime risk of major depression. International journal of epidemiology, 2002. 31(2): p. 359-367.

144. Stansfeld, S.A. and M.G. Marmot, Social class and minor psychiatric disorder in British Civil Servants: a validated screening survey using the General Health Questionnaire. Psychological Medicine, 1992. 22: p. 739749.

145. Zimmerman, F.J. and W. Katon, Socioeconomic status, depression disparities, and financial strain: what lies behind the income-depression relationship? Health Economics 2005. 14(12): p. 1197-1215. 
146. Brooks-Gunn, J., J.A. Graber, and R.L. Paikoff, Studying Links Between Hormones and Negative Affect: Models and Measures. Journal of Research on Adolescence, 1994. 4(4): p. 469-486.

147. Graber, J.A. and J. Brooks-Gunn, Adolescent Girls’ Sexual Development. Handbook of Women's Sexual and Reproductive Health. 2002, New York, NY: Kluwer Academic/Plenum. 21-42.

148. Brooks-Gunn, J., A.C. Petersen, and D. Eichorn, The study of maturational timing effects in adolescence. Journal of Youth and Adolescence, 1985. 14(3): p. 149-161.

149. DeRose, L.M. and J. Brooks-Gunn, Pubertal development in early adolescence: implications for affective processes. Adolescent Emotional Development and the Emergence of Depressive Disorders, ed. N.B. Allen and L.B. Sheeber. 2012, New York, NY: Cambridge University Press

150. Ge, X., R.D. Conger, and G.H. Elder, Coming of Age Too Early: Pubertal Influences on Girls' Vulnerability to Psychological Distress. Child Development, 1996. 67(6): p. 3386-3400.

151. Graber, J.A., et al., Is Pubertal Timing Associated With Psychopathology in Young Adulthood? Journal of the American Academy of Child \& Adolescent Psychiatry, 2004. 43(6): p. 718-726.

152. Caspi, A. and T.E. Moffitt, Individual differences are accentuated during periods of social change: The sample case of girls at puberty. Journal of Personality and Social Psychology, 1991. 61(1): p. 157-168. 
(c) Lesa K. Ellis and Mary K. Rothbart, 1999

\section{Early Adolescent Temperament Questionnaire - Revised Adolescent Self-Report}

\section{Directions}

On the following page you will find a series of statements that people might use to describe themselves. The statements refer to a wide number of activities and attitudes.

For each statement, please circle the answer that best describes how true each statement is for you. There are no best answers. People are very different in how they feel about these statements. Please circle the first answer that comes to you.

You will use the following scale to describe how true or false a statement is about you:

\section{Circle number:}

1

2

3

4

5

\section{If the statement is:}

Almost always untrue of you

Usually untrue of you

Sometimes true, sometimes untrue of you

Usually true of you

Almost always true of you

NOTE: Please make certain to answer all questions on BOTH SIDES of the page.

Please tell us:

Your date of birth:

Your gender: $\mathbf{M}$ / F

Family ID code (please leave blank) 


\begin{tabular}{|c|c|c|c|c|c|}
\hline How true is each statement for you? & $\begin{array}{l}\text { Almost } \\
\text { always } \\
\text { untrue }\end{array}$ & $\begin{array}{l}\text { Usually } \\
\text { untrue }\end{array}$ & $\begin{array}{c}\text { Sometimes } \\
\text { true, } \\
\text { sometimes } \\
\text { untrue }\end{array}$ & $\begin{array}{l}\text { Usually } \\
\text { true }\end{array}$ & $\begin{array}{c}\text { Almost } \\
\text { always } \\
\text { true }\end{array}$ \\
\hline $\begin{array}{l}\text { 1) It is easy for me to really concentrate on } \\
\text { homework problems. }\end{array}$ & 1 & 2 & 3 & 4 & 5 \\
\hline 2) I feel pretty happy most of the day. & 1 & 2 & 3 & 4 & 5 \\
\hline $\begin{array}{l}\text { 3) I think it would be exciting to move to a new } \\
\text { city. }\end{array}$ & 1 & 2 & 3 & 4 & 5 \\
\hline $\begin{array}{l}\text { 4) I like to feel a warm breeze blowing on my } \\
\text { face. }\end{array}$ & 1 & 2 & 3 & 4 & 5 \\
\hline $\begin{array}{l}\text { 5) If I'm mad at somebody, I tend to say things } \\
\text { that I know will hurt their feelings. }\end{array}$ & 1 & 2 & 3 & 4 & 5 \\
\hline $\begin{array}{l}\text { 6) I notice even little changes taking place } \\
\text { around me, like lights getting brighter in a } \\
\text { room. }\end{array}$ & 1 & 2 & 3 & 4 & 5 \\
\hline 7) I have a hard time finishing things on time. & 1 & 2 & 3 & 4 & 5 \\
\hline 8) I feel shy with kids of the opposite sex. & 1 & 2 & 3 & 4 & 5 \\
\hline 9) When I am angry, I throw or break things. & 1 & 2 & 3 & 4 & 5 \\
\hline $\begin{array}{l}\text { 10) It's hard for me not to open presents before } \\
\text { I'm supposed to. }\end{array}$ & 1 & 2 & 3 & 4 & 5 \\
\hline $\begin{array}{l}\text { 11) My friends seem to enjoy themselves more } \\
\text { than I do. }\end{array}$ & 1 & 2 & 3 & 4 & 5 \\
\hline $\begin{array}{l}\text { 12) I tend to notice little changes that other } \\
\text { people do not notice. }\end{array}$ & 1 & 2 & 3 & 4 & 5 \\
\hline $\begin{array}{l}\text { 13) If I get really mad at someone, I might hit } \\
\text { them. }\end{array}$ & 1 & 2 & 3 & 4 & 5 \\
\hline $\begin{array}{l}\text { 14) When someone tells me to stop doing } \\
\text { something, it is easy for me to stop. }\end{array}$ & 1 & 2 & 3 & 4 & 5 \\
\hline 15) I feel shy about meeting new people. & 1 & 2 & 3 & 4 & 5 \\
\hline 16) I enjoy listening to the birds sing. & 1 & 2 & 3 & 4 & 5 \\
\hline $\begin{array}{l}\text { 17) I want to be able to share my private thoughts } \\
\text { with someone else. }\end{array}$ & 1 & 2 & 3 & 4 & 5 \\
\hline $\begin{array}{l}\text { 18) I do something fun for a while before starting } \\
\text { my homework, even when l'm not supposed } \\
\text { to. }\end{array}$ & 1 & 2 & 3 & 4 & 5 \\
\hline $\begin{array}{l}\text { 19) I wouldn't like living in a really big city, even if } \\
\text { it was safe. }\end{array}$ & 1 & 2 & 3 & 4 & 5 \\
\hline $\begin{array}{l}\text { 20) It often takes very little to make me feel like } \\
\text { crying. }\end{array}$ & 1 & 2 & 3 & 4 & 5 \\
\hline 21) I am very aware of noises. & 1 & 2 & 3 & 4 & 5 \\
\hline 22) I tend to be rude to people I don't like. & 1 & 2 & 3 & 4 & 5 \\
\hline $\begin{array}{l}\text { 23) I like to look at the pattern of clouds in the } \\
\text { sky. }\end{array}$ & 1 & 2 & 3 & 4 & 5 \\
\hline $\begin{array}{l}\text { 24) I can tell if another person is angry by their } \\
\text { expression. }\end{array}$ & 1 & 2 & 3 & 4 & 5 \\
\hline $\begin{array}{l}\text { 25) It bothers me when I try to make a phone call } \\
\text { and the line is busy. }\end{array}$ & 1 & 2 & 3 & 4 & 5 \\
\hline $\begin{array}{l}\text { 26) The more I try to stop myself from doing } \\
\text { something I shouldn't, the more likely I am to } \\
\text { do it. }\end{array}$ & 1 & 2 & 3 & 4 & 5 \\
\hline 27) I enjoy exchanging hugs with people I like. & 1 & 2 & 3 & 4 & 5 \\
\hline $\begin{array}{l}\text { 28) Skiing fast down a steep slope sounds scary } \\
\text { to me. }\end{array}$ & 1 & 2 & 3 & 4 & 5 \\
\hline 29) I get sad more than other people realize. & 1 & 2 & 3 & 4 & 5 \\
\hline $\begin{array}{l}\text { 30) If I have a hard assignment to do, I get } \\
\text { started right away. }\end{array}$ & 1 & 2 & 3 & 4 & 5 \\
\hline
\end{tabular}




\begin{tabular}{|c|c|c|c|c|c|}
\hline How true is each statement for you? & $\begin{array}{l}\text { Almost } \\
\text { always } \\
\text { untrue }\end{array}$ & $\begin{array}{l}\text { Usually } \\
\text { untrue }\end{array}$ & $\begin{array}{c}\text { Sometimes } \\
\text { true, } \\
\text { sometimes } \\
\text { untrue }\end{array}$ & $\begin{array}{l}\text { Usually } \\
\text { true }\end{array}$ & $\begin{array}{l}\text { Almost } \\
\text { always } \\
\text { true }\end{array}$ \\
\hline $\begin{array}{l}\text { 31) I will do most anything to help someone I care } \\
\text { about. }\end{array}$ & 1 & 2 & 3 & 4 & 5 \\
\hline $\begin{array}{l}\text { 32) I get frightened riding with a person who likes } \\
\text { to speed. }\end{array}$ & 1 & 2 & 3 & 4 & 5 \\
\hline 33) I like to look at trees and walk amongst them. & 1 & 2 & 3 & 4 & 5 \\
\hline $\begin{array}{l}\text { 34) I find it hard to shift gears when I go from one } \\
\text { class to another at school. }\end{array}$ & 1 & 2 & 3 & 4 & 5 \\
\hline $\begin{array}{l}\text { 35) I worry about my family when I'm not with } \\
\text { them. }\end{array}$ & 1 & 2 & 3 & 4 & 5 \\
\hline $\begin{array}{l}\text { 36) I get very upset if I want to do something } \\
\text { and my parents won't let me. }\end{array}$ & 1 & 2 & 3 & 4 & 5 \\
\hline $\begin{array}{l}\text { 37) I get sad when a lot of things are going } \\
\text { wrong. }\end{array}$ & 1 & 2 & 3 & 4 & 5 \\
\hline $\begin{array}{l}\text { 38) When trying to study, I have difficulty tuning } \\
\text { out background noise and concentrating. }\end{array}$ & 1 & 2 & 3 & 4 & 5 \\
\hline 39) I finish my homework before the due date. & 1 & 2 & 3 & 4 & 5 \\
\hline 40) I worry about getting into trouble. & 1 & 2 & 3 & 4 & 5 \\
\hline $\begin{array}{l}\text { 41) I am good at keeping track of several different } \\
\text { things that are happening around me. }\end{array}$ & 1 & 2 & 3 & 4 & 5 \\
\hline $\begin{array}{l}\text { 42) I would not be afraid to try a risky sport, like } \\
\text { deep-sea diving. }\end{array}$ & 1 & 2 & 3 & 4 & 5 \\
\hline 43) It's easy for me to keep a secret. & 1 & 2 & 3 & 4 & 5 \\
\hline $\begin{array}{l}\text { 44) It is important to me to have close } \\
\text { relationships with other people. }\end{array}$ & 1 & 2 & 3 & 4 & 5 \\
\hline 45) I am shy. & 1 & 2 & 3 & 4 & 5 \\
\hline $\begin{array}{l}\text { 46) I am nervous of some of the kids at school } \\
\text { who push people into lockers and throw your } \\
\text { books around. }\end{array}$ & 1 & 2 & 3 & 4 & 5 \\
\hline $\begin{array}{l}\text { 47) I get irritated when I have to stop doing } \\
\text { something that I am enjoying. }\end{array}$ & 1 & 2 & 3 & 4 & 5 \\
\hline $\begin{array}{l}\text { 48) I wouldn't be afraid to try something like } \\
\text { mountain climbing. }\end{array}$ & 1 & 2 & 3 & 4 & 5 \\
\hline $\begin{array}{l}\text { 49) I put off working on projects until right before } \\
\text { they're due. }\end{array}$ & 1 & 2 & 3 & 4 & 5 \\
\hline $\begin{array}{l}\text { 50) When I'm really mad at a friend, I tend to } \\
\text { explode at them. }\end{array}$ & 1 & 2 & 3 & 4 & 5 \\
\hline $\begin{array}{l}\text { 51) I worry about my parent(s) dying or leaving } \\
\text { me. }\end{array}$ & 1 & 2 & 3 & 4 & 5 \\
\hline $\begin{array}{l}\text { 52) I enjoy going places where there are big } \\
\text { crowds and lots of excitement. }\end{array}$ & 1 & 2 & 3 & 4 & 5 \\
\hline 53) I am not shy. & 1 & 2 & 3 & 4 & 5 \\
\hline 54) I am quite a warm and friendly person. & 1 & 2 & 3 & 4 & 5 \\
\hline $\begin{array}{l}\text { 55) I feel sad even when I should be enjoying } \\
\text { myself, like at Christmas or on a trip. }\end{array}$ & 1 & 2 & 3 & 4 & 5 \\
\hline 56) It really annoys me to wait in long lines. & 1 & 2 & 3 & 4 & 5 \\
\hline $\begin{array}{l}\text { 57) I feel scared when I enter a darkened room at } \\
\text { home. }\end{array}$ & 1 & 2 & 3 & 4 & 5 \\
\hline 58) I pick on people for no real reason. & 1 & 2 & 3 & 4 & 5 \\
\hline $\begin{array}{l}\text { 59) I pay close attention when someone tells me } \\
\text { how to do something. }\end{array}$ & 1 & 2 & 3 & 4 & 5 \\
\hline $\begin{array}{l}\text { 60) I get very frustrated when I make a mistake in } \\
\text { my school work. }\end{array}$ & 1 & 2 & 3 & 4 & 5 \\
\hline $\begin{array}{l}\text { 61) I tend to get in the middle of one thing, then } \\
\text { go off and do something else. }\end{array}$ & 1 & 2 & 3 & 4 & 5 \\
\hline
\end{tabular}




\begin{tabular}{|l|c|c|c|c|c|}
\hline How true is each statement of you? & $\begin{array}{c}\text { Almost } \\
\text { always } \\
\text { untrue }\end{array}$ & $\begin{array}{c}\text { Usually } \\
\text { untrue }\end{array}$ & $\begin{array}{c}\text { Sometimes } \\
\text { true, } \\
\text { sometimes } \\
\text { untrue }\end{array}$ & $\begin{array}{c}\text { Usually } \\
\text { true }\end{array}$ & $\begin{array}{c}\text { Almost } \\
\text { always } \\
\text { true }\end{array}$ \\
\hline $\begin{array}{c}\text { 62) It frustrates me if people interrupt me when } \\
\text { l'm talking. }\end{array}$ & 1 & 2 & 3 & 4 & 5 \\
\hline 63 I can stick with my plans and goals. & 1 & 2 & 3 & 4 & 5 \\
\hline $\begin{array}{c}64) \text { I get upset if l'm not able to do a task really } \\
\text { well. }\end{array}$ & 1 & 2 & 3 & 4 & 5 \\
\hline 65$)$ I like the crunching sound of autumn leaves. & 1 & 2 & 3 & 4 & 5 \\
\hline
\end{tabular}




\section{Center for Epidemiologic Studies Depression Scale (CES-D), NIMH}

Below is a list of the ways you might have felt or behaved. Please tell me how often you have felt this way during the past week.

\begin{tabular}{|c|c|c|c|c|}
\hline & \multicolumn{4}{|c|}{ During the Past } \\
\hline & $\begin{array}{c}\text { Rarely or none of } \\
\text { the time (less than } \\
1 \text { day) }\end{array}$ & $\begin{array}{c}\text { Some or a } \\
\text { little of the } \\
\text { time (1-2 } \\
\text { days) }\end{array}$ & $\begin{array}{l}\text { Occasionally or a } \\
\text { moderate amount of time } \\
\text { (3-4 days) }\end{array}$ & $\begin{array}{l}\text { Most or all of } \\
\text { the time (5-7 } \\
\text { days) }\end{array}$ \\
\hline $\begin{array}{l}\text { 1. I was bothered by things that usually } \\
\text { don't bother me. }\end{array}$ & $\square$ & $\square$ & $\square$ & $\square$ \\
\hline $\begin{array}{l}\text { 2. I did not feel like eating; my appetite } \\
\text { was poor. }\end{array}$ & $\square$ & $\square$ & $\square$ & $\square$ \\
\hline $\begin{array}{l}\text { 3. I felt that I could not shake off the } \\
\text { blues even with help trom my tamily or } \\
\text { friends. }\end{array}$ & $\square$ & $\square$ & $\square$ & $\square$ \\
\hline $\begin{array}{l}\text { 4. I felt I was just as good as other } \\
\text { people. }\end{array}$ & $\square$ & $\square$ & $\square$ & L \\
\hline $\begin{array}{l}\text { 5. I had trouble keeping my mind on } \\
\text { what I was doing. } \\
6 \text {. I felt depressed. }\end{array}$ & $\square$ & $\square$ & $\square$ & $\square$ \\
\hline $\begin{array}{l}\text { 7. I felt that everything I did was an } \\
\text { effort. }\end{array}$ & L & L & $\square$ & $\square$ \\
\hline 8. I felt hopeful about the future. & $\square$ & $\square$ & $\square$ & 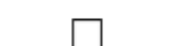 \\
\hline 9. I thought my life had been a failure. & $L$ & 5 & $\Pi$ & 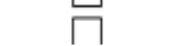 \\
\hline 10. I felt fearful. & & 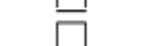 & 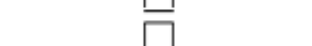 & 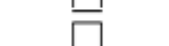 \\
\hline 11. My sleep was restless. & & 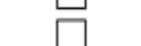 & & 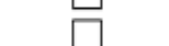 \\
\hline 12. I was happy. & $\Gamma$ & 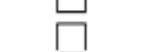 & 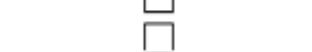 & \\
\hline 13. I talked less than usual. & & 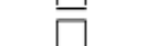 & $\square$ & \\
\hline 14. I felt lonely. & 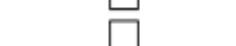 & 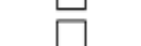 & 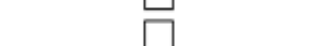 & \\
\hline 15. People were unfriendly. & 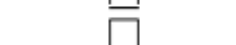 & $\square$ & $\square$ & 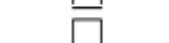 \\
\hline 16. I enjoyed life. & & 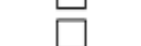 & $\square$ & ए \\
\hline 17. I had crying spells. & $\Gamma$ & $\Pi$ & $\Pi$ & 1 \\
\hline 18. I felt sad. & $\square$ & $\square$ & $\square$ & 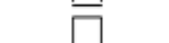 \\
\hline 19. I felt that people dislike me. & 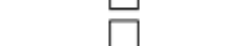 & 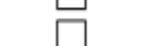 & 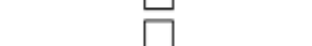 & $\square$ \\
\hline 20. I could not get "going." & $\square$ & $\square$ & $\square$ & $\square$ \\
\hline
\end{tabular}

SCORING: zero for answers in the first column, 1 for answers in the second column, 2 for answers in the third column, 3 for answers in the fourth column. The scoring of positive items is reversed. Possible range of scores is zero to 60 , with the higher scores indicating the presence of more symptomatology. 


\section{BAI}

INSTRUCTIONS: Below is a list of common symptoms of anxiety. Please read each item in the list carefully. Indicate how much you have been bothered by each symptom during the PAST WEEK, INCLUDING TODAY by circling the corresponding number in the column next to each symptom.

\begin{tabular}{|c|c|c|c|c|}
\hline & $\frac{\text { Not }}{\text { at all }}$ & $\begin{array}{l}\text { Mildly } \\
\text { It did not } \\
\text { bother me } \\
\text { much }\end{array}$ & $\begin{array}{c}\text { Moderately } \\
\text { It was very } \\
\text { unpleasant but } \\
\text { I could stand it }\end{array}$ & $\begin{array}{l}\frac{\text { Severely }}{\text { I could }} \\
\text { barely } \\
\text { stand it }\end{array}$ \\
\hline 1. Numbness or tingling & 0 & 1 & 2 & 3 \\
\hline 2. Feeling hot & 0 & 1 & 2 & 3 \\
\hline 3. Wobbliness in legs & 0 & 1 & 2 & 3 \\
\hline 4. Unable to relax & 0 & 1 & 2 & 3 \\
\hline 5. Fear of the worst happening & 0 & 1 & 2 & 3 \\
\hline 6. Dizzy or lightheaded & 0 & 1 & 2 & 3 \\
\hline 7. Heart pounding or racing & 0 & 1 & 2 & 3 \\
\hline 8. Unsteady & 0 & 1 & 2 & 3 \\
\hline 9. Terrified & 0 & 1 & 2 & 3 \\
\hline 10. Nervous & 0 & 1 & 2 & 3 \\
\hline 11. Feeling of choking & 0 & 1 & 2 & 3 \\
\hline 12. Hands trembling & 0 & 1 & 2 & 3 \\
\hline 13. Shaky & 0 & 1 & 2 & 3 \\
\hline 14. Fear of losing control; & 0 & 1 & 2 & 3 \\
\hline 15. Difficulty breathing & 0 & 1 & 2 & 3 \\
\hline 16. Fear of dying & 0 & 1 & 2 & 3 \\
\hline 17. Scared & 0 & 1 & 2 & 3 \\
\hline $\begin{array}{l}\text { 18. Indigestion or discomfort } \\
\text { in abdomen }\end{array}$ & 0 & 1 & 2 & 3 \\
\hline 19. Faint & 0 & 1 & 2 & 3 \\
\hline 20. Face flushed & 0 & 1 & 2 & 3 \\
\hline 21. Sweating (not due to heat) & 0 & 1 & 2 & 3 \\
\hline
\end{tabular}




\section{CBCL-Parent}

Below is a list of items that describe children and youth. For each item that describes your child now or within the past 6 months, please circle the 2 if the items is very true or often true of your child. Circle the 1 if the item is somewhat or sometimes true of your child. If the item is not true of your child, circle the 0 . Please answer all items as well as you can, even if some do not seem to apply to your child.

$0=$ Not True (as far as you know) $\quad 1=$ Somewhat or Sometimes True $\quad 2=$ Very True or Often True

1. Acts too young for his/her age 0

2. Argues a lot

3. Bragging, boasting

4. Can't concentrate, can't pay attention for long

5. Can't sit still, restless, or hyperactive

6. Clings to adults or too dependent

7. Confused or seems to be in a fog

8. Cruelty, bullying, or meanness to others

9. Day-dreams or gets lost in his/her thoughts

10. Demands a lot of attention

11. Destroys his/her own things

12. Destroys things belonging to his/her family or others

13. Disobedient at home

14. Disobedient at school

15. Doesn't get along with other kids

16. Doesn't seem to feel guilty after misbehaving

17. Easily jealous

18. Gets teased a lot

19. Hangs around with others who get in trouble

20. Impulsive or acts without thinking

21. Lying or cheating

22. Nervous, highstrung, or tense

23. Nervous movements or twitching (describe):

$\begin{array}{lll}0 & 1 & 2 \\ 0 & 1 & 2 \\ 0 & 1 & 2 \\ 0 & 1 & 2 \\ 0 & 1 & 2 \\ 0 & 1 & 2 \\ 0 & 1 & 2 \\ 0 & 1 & 2 \\ 0 & 1 & 2 \\ 0 & 1 & 2 \\ 0 & 1 & 2 \\ 0 & 1 & 2 \\ 0 & 1 & 2 \\ 0 & 1 & 2 \\ 0 & 1 & 2 \\ 0 & 1 & 2 \\ 0 & 1 & 2 \\ 0 & 1 & 2 \\ 0 & 1 & 2 \\ 0 & 1 & 2 \\ 0 & 1 & 2 \\ 0 & 1 & 2 \\ 0 & 1 & \end{array}$

\begin{tabular}{|c|c|c|}
\hline 24. Not liked by other kids & 0 & 1 \\
\hline 25. Overweight & 0 & 1 \\
\hline 26. Physically attacks people & 0 & 1 \\
\hline 27. Poor school work & 0 & 1 \\
\hline 28. Poorly coordinated or clumsy & 0 & 1 \\
\hline 29. Gets in many fights & 0 & 1 \\
\hline 30. Prefers being with older kids & 0 & 1 \\
\hline 31. Prefers being with younger kids & 0 & 1 \\
\hline 32. Runs away from home & 0 & 1 \\
\hline 33. Sets fires & 0 & 1 \\
\hline 34. Showing off or clowning & 0 & 1 \\
\hline 35. Stares blankly & 0 & 1 \\
\hline 36. Steals at home & 0 & 1 \\
\hline 37. Steals outside the home & 0 & 1 \\
\hline 38. Stubborn, sullen, or irritable & 0 & 1 \\
\hline 39. Sudden changes in mood or feelings & 0 & 1 \\
\hline 40. Screams a lot & 0 & 1 \\
\hline 41. Swearing or obscene language & 0 & 1 \\
\hline 42. Talks too much & 0 & 1 \\
\hline 43. Teases a lot & 0 & 1 \\
\hline 44. Temper tantrums or hot temper & 0 & 1 \\
\hline 45. Thinks about sex too much & 0 & 1 \\
\hline 46. Threatens people & 0 & 1 \\
\hline 47. Truancy, skips school & 0 & 1 \\
\hline 48. Unusually loud & 0 & 1 \\
\hline 49. Uses alcohol or drugs for nonmedical purposes (describe): & 0 & 1 \\
\hline 50. Vandalism & 0 & 1 \\
\hline
\end{tabular}




\section{Scales}

\section{Social Problems}

1. Acts too young for his/her age

6. Clings to adults or too dependent

15. Doesn't get along with other kids

18. Gets teased a lot

24. Not liked by other kids

25. Overweight

28. Poorly coordinated or clumsy

31. Prefers being with younger kids

\section{Attention Problems}

1. Acts too young for his/her age

4. Can't concentrate, can't pay attention for long

5. Can't sit still, restless, or hyperactive

7. Confused or seems to be in a fog

9. Day-dreams or gets lost in his/her thoughts

20. Impulsive or acts without thinking

22. Nervous, highstrung, or tense

23. Nervous movements or twitching (describe):

$\longrightarrow$

27. Poor school work

35. Stares blankly

\section{Delinquent Behavior}

16. Doesn't seem to feel guilty after misbehaving

19. Hangs around with others who get in trouble

21. Lying or cheating

30. Prefers being with older kids

32. Runs away from home

33. Sets fires

36. Steals at home

37. Steals outside the home

41. Swearing or obscene language

45. Thinks about sex too much

47. Truancy, skips school

49. Uses alcohol or drugs for nonmedical purposes (describe):

50. Vandalism

\section{Aggressive Behavior}

2. Argues a lot

3. Bragging, boasting

8. Cruelty, bullying, or meanness to others

10. Demands a lot of attention

11. Destroys his/her own things

12. Destroys things belonging to his/her family or others

13. Disobedient at home

14. Disobedient at school

17. Easily jealous

29. Gets in many fights

26. Physically attacks people

34. Showing off or clowning

38. Stubborn, sullen, or irritable

39. Sudden changes in mood or feelings

40. Screams a lot

42. Talks too much

43. Teases a lot

44. Temper tantrums or hot temper

46. Threatens people

48. Unusually loud 